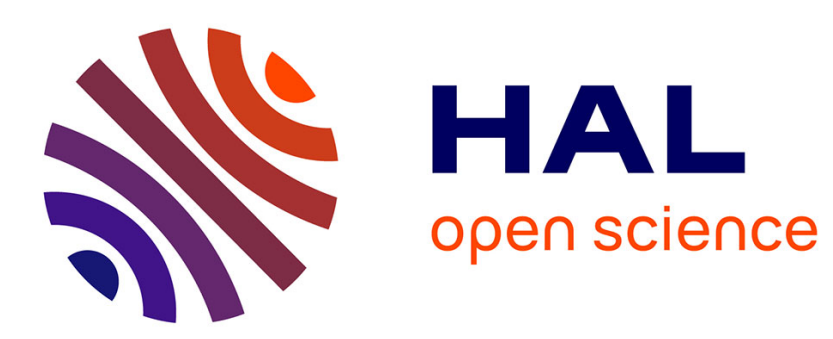

\title{
Effect of salinity and nanoparticle polydispersity on UF membrane retention fouling
}

\author{
Morgane Le Hir, Yvan Wyart, Gaëlle Georges, Laure Siozade Lamoine, \\ Patrick Sauvade, Philippe Moulin
}

\section{- To cite this version:}

Morgane Le Hir, Yvan Wyart, Gaëlle Georges, Laure Siozade Lamoine, Patrick Sauvade, et al.. Effect of salinity and nanoparticle polydispersity on UF membrane retention fouling. Journal of Membrane Science, 2018, 563, pp.405-418. 10.1016/j.memsci.2018.05.077 . hal-02114445

\section{HAL Id: hal-02114445 \\ https://hal.science/hal-02114445}

Submitted on 29 Apr 2019

HAL is a multi-disciplinary open access archive for the deposit and dissemination of scientific research documents, whether they are published or not. The documents may come from teaching and research institutions in France or abroad, or from public or private research centers.
L'archive ouverte pluridisciplinaire HAL, est destinée au dépôt et à la diffusion de documents scientifiques de niveau recherche, publiés ou non, émanant des établissements d'enseignement et de recherche français ou étrangers, des laboratoires publics ou privés. 


\title{
Effect of salinity and nanoparticle polydispersity on UF membrane retention fouling
}

\author{
Morgane Le Hir ${ }^{\mathrm{a}}$, Yvan Wyart ${ }^{\mathrm{a}}$, Gaëlle Georges ${ }^{\mathrm{b}}$, Laure Siozade Lamoine ${ }^{\mathrm{b}}$, Patrick Sauvade ${ }^{\mathrm{c}}$, \\ Philippe Moulin ${ }^{\text {a,* }}$
}

a Aix Marseille Université, CNRS, Centrale Marseille, M2P2 UMR 7340, Equipe Procédés Membranaires (EPM), Europôle de l'Arbois, BP80, Pavillon Laennec, Hall C, 13545 Aix en Provence Cedex, France

${ }^{\mathrm{b}}$ Aix Marseille Univ, CNRS, Centrale Marseille, Institut Fresnel, Marseille, France

${ }^{c}$ Suez-Aquasource, 20 Avenue Didier Daurat - BP64050, 31029 Toulouse Cedex 4, France

\section{A R T I C L E I N F O}

\section{Keywords:}

Ultrafiltration

Fluorescent nanoparticles

Membrane fouling

Polydispersity

Salinity

\begin{abstract}
A B S T R A C T
In this study, the retention potential and the fouling of ultrafiltration (UF) multichannel hollow fiber membrane regarding nanoparticles (NPs) have been assessed. Filtration experiments of fluorescent $10 \mathrm{~nm}$ and $1.5 \mathrm{~nm}$ NPs (respectively NP-10 and NP-1.5) suspensions filtered individually were carried out under different transmembrane pressures. A complexification of the feed suspension through the mix of NPs sizes and/or the salinity adding have been investigated. The retention rate (RR), the fouling location and the membrane productivity have been analyzed and compared in each case to determine the influence of salinity and polydispersity of the feed suspensions on NP retention. Results show that RR of NP-10 stays constant when NPs are filtered in ideal suspension (NP-10 / ultrapure water), or when they are filtered with NP-1.5 and/or with $50 \mathrm{mmol} \mathrm{L}^{-1} \mathrm{of} \mathrm{NaCl}^{-1}$ and reaches at least $99 \%$. However, RR of NP-1.5 is modified by the presence of NP-10 and/or $50 \mathrm{mmol} \mathrm{L}^{-1}$ of $\mathrm{NaCl}$. This retention rate is considerably decreased by the complexification of suspensions tested. Estimation of NPs quantity blocked at the membrane at the end of the filtration by mass balance showed no significative variation for NP-1.5 (relative to the RR obtained) while a larger quantity of NP-10 remained blocked at the membrane with the adding of NP-1.5 and/or salts in feed suspension. Location of NPs by Confocal Laser Scanning Microscopy (CLSM) at the end of the filtration showed that filtered individually, NP-10 are blocked in membrane skin and on membrane surface while NP-1.5 are blocked in the entire membrane material. Filtered simultaneously, the location of these two sizes of NPs is not modified but NP-1.5 seems to form clusters in the membrane material and the participation of NP-10 and NP-1.5 to the deposit formed on the membrane surface is increased. The adding of salinity leads to the same observations than the filtration of both sizes mixed.
\end{abstract}

\section{Introduction}

Nanoparticles (NPs) retention by ultrafiltration (UF) membrane presents a great interest since few decades due to the emergence of this new pollution in natural waters used to produce drinking water. NPs are defined like particles presenting at least one dimension less than or equal to $100 \mathrm{~nm}$. The nanoscale offers to NPs new interesting properties - color, resistance, thermic properties, reactivity - making that they are more and more used in various sector of activity. This increase of production and use of NPs leads to an uncontrolled release into the environment during the entire NPs life cycle, going from their production to their transport, their storage, their use or their recycling [1]. This NPs release affects air, soil and water [2], especially surface waters which are used to produce drinking water. Currently, few quantitative data are available about the nature, size and concentrations of nanomaterials emitted in the environment. Only few studies transcribe NPs concentrations that could be found in the environment, often based on emission modeling [3-6]. In these scenarios, the authors consider the emission of various NP materials, inorganic $\left(\mathrm{Ag}, \mathrm{Ti} / \mathrm{TiO}_{2}, \mathrm{ZnO}, \mathrm{CeO}_{2}\right.$, quantum dots...) or organic (carbon nanotube, fullerene, carbon black...) and results obtained may show important variation of concentrations. Table 1 sums up quantity announced by diverse modeling tested.

The study of Peters et al. [7] is one of the first to have successfully quantified NPs present in Dutch surface water at low environmental concentrations. They used ICP-MS to realize a qualitative analysis of water samples. The particles number and sizes as well as mass concentrations were calculated from their results using calculation tool

\footnotetext{
* Corresponding author.

E-mail address: philippe.moulin@univ-amu.fr (P. Moulin).
} 
Table 1

Estimation by modeling of nanomaterials concentrations in surface waters.

\begin{tabular}{|c|c|c|c|}
\hline Nanomaterial & $\begin{array}{l}\text { Modeled concentrations in surface } \\
\text { waters }\end{array}$ & Units & Ref \\
\hline \multicolumn{4}{|l|}{ Inorganic } \\
\hline \multirow{3}{*}{$\mathrm{Ag}$} & $0.1-3.0$ & $\mathrm{ng} \mathrm{L} \mathrm{L}^{-1}$ & [5] \\
\hline & $0.37-0.94$ & $n g L^{-1}$ & [4] \\
\hline & $0-44$ & $\mathrm{pgL}^{-1}$ & [3] \\
\hline $\mathrm{Ti} / \mathrm{TiO}_{2}$ & $2.0-85.0$ & $\mathrm{ng} \mathrm{L}^{-1}$ & [5] \\
\hline photostable $\mathrm{TiO}_{2}$ & $0.6-100$ & $\mathrm{ng} \mathrm{L}^{-1}$ & [3] \\
\hline Photocatalytic $\mathrm{TiO}_{2}$ & $0.09-7$ & $\mathrm{ng} \mathrm{L} \mathrm{L}^{-1}$ & [3] \\
\hline \multirow{4}{*}{$\mathrm{ZnO}$} & $400-3000$ & $\mathrm{ng} \mathrm{L}^{-1}$ & [4] \\
\hline & $1.0-58.0$ & $\mathrm{ng} \mathrm{L}^{-1}$ & [5] \\
\hline & $0.09-13$ & $\mathrm{ng} \mathrm{L}^{-1}$ & [3] \\
\hline & $50-610$ & $\mathrm{ng} \mathrm{L} \mathrm{L}^{-1}$ & [4] \\
\hline $\mathrm{CeO}_{2}$ & $0.6-100$ & $\mathrm{pg} \mathrm{L}^{-1}$ & [3] \\
\hline $\mathrm{Al}_{2} \mathrm{O}_{3}$ & 0.2 & $\mathrm{ng} \mathrm{L}^{-1}$ & [6] \\
\hline $\mathrm{Au}$ & 140 & $\mathrm{ng} \mathrm{L}^{-1}$ & [6] \\
\hline $\mathrm{SiO}_{2}$ & 0.7 & $\mathrm{ng} \mathrm{L}^{-1}$ & [6] \\
\hline QD & $<1$ & $\mathrm{fg} \mathrm{L}^{-1}$ & [3] \\
\hline \multicolumn{4}{|l|}{ Organic } \\
\hline \multirow[t]{3}{*}{ Carbone nanotubes } & $6 \times 10^{-4}-2.5 \times 10^{-2}$ & $n g L^{-1}$ & [5] \\
\hline & $0.2-15$ & $\mathrm{pg} \mathrm{L}^{-1}$ & [3] \\
\hline & $0.17-0.56$ & $\mathrm{ng} \mathrm{L}^{-1}$ & [4] \\
\hline \multirow[t]{3}{*}{ Fullerene } & $2.4 \times 10^{-3}-0.2$ & $\mathrm{ng} \mathrm{L}^{-1}$ & [5] \\
\hline & 310 & $n g L^{-1}$ & [6] \\
\hline & $0.07-0.33$ & $\mathrm{ng} \mathrm{L}^{-1}$ & {$[2]$} \\
\hline Organic silica & 0.5 & $\mathrm{ng} \mathrm{L}^{-1}$ & [6] \\
\hline Carbon Black (CB) & $100-6000$ & $\mathrm{ng} \mathrm{L}^{-1}$ & [3] \\
\hline
\end{tabular}

developed previously [8-10]. The authors confirm the presence of nanoparticles of $\mathrm{Ag}$ and $\mathrm{CeO}_{2}$ (with sizes between 14 and $21 \mathrm{~nm}$ ) and micro-sized $\mathrm{TiO}_{2}$ (from 250 to $340 \mathrm{~nm}$ ) particles in surface waters and this study showed that particles concentrations range may reach from $0.8 \mathrm{ng} \mathrm{L}^{-1}$ for $\mathrm{Ag}$ to $3.1 \mu \mathrm{g} \mathrm{L}^{-1}$ for $\mathrm{TiO}_{2}$.

The properties obtained at the nanoscale are still poorly known. The increase of reactivity could be the cause of an important toxicity [11-14]. In fact, a lot of parameters have to be taken into account to evaluate the toxicity: the dose of NP considered, the material, the size, the way of contact with the organism, etc. However, some studies highlight that the emergence of NPs pose a potential health risk [11-14]. That is why this new pollution must be considered, especially in the scheme of drinking water production. Wu et al. [10] showed that several processes allow to retain nanomaterial, especially processes used in drinking water production plant like chemical coagulation or granular filtration. However, many factors affect the removal efficiency (water composition, coagulant type and dosage, flow condition, granular medium, etc...). The pore size of ultrafiltration (UF) membrane generally between 1 and $100 \mathrm{~nm}$ (Molecular Weight Cut-Off (MWCO) between 2 and $300 \mathrm{kDa}$ ) offer to this process a real retention potential towards NPs. Guo et al. [15] have shown, in an UF membrane integrity test, that magnetic nanoparticles $\left(\mathrm{Fe}_{3} \mathrm{O}_{4}\right)$ with an average size of about $35 \mathrm{~nm}$ can be fully retained by hollow fiber membranes with nominal pore size of $25 \mathrm{~nm}$ (MWCO of $150 \mathrm{kDa}$ ) during dead-end or tangential filtration under low transmembrane pressure (TMP) of $0.25 \mathrm{bar}$. Wu et al. [16] have shown that NPs of sizes between $1.5 \mathrm{~nm}$ and $4.5 \mathrm{~nm}$ are completely retained by flat membranes with cut-off from $1 \mathrm{kDa}$ to $10 \mathrm{kDa}$ (pore size estimated from $1.58 \mathrm{~nm}$ to $5.37 \mathrm{~nm}$ ) under a TMP of 2 bar. Retention of these NPs, on the other hand, vary from about $10-95 \%$ when they are filtered by $30 \mathrm{kDa}$ membranes (pore size estimated to $9.61 \mathrm{~nm}$ ) under the same TMP. However, like it is shown by Chen et al. [17], NPs much smaller than membrane pore size may be partially retained. For example, for ratios of particle size to pore size from 0.13 to 0.004 (by filtering $1.7 \mathrm{~nm}$ and $6.6 \mathrm{~nm}$ quantum dots on 50 and $100 \mathrm{~nm}$ membranes), initial retention efficiency from $30 \%$ to $60 \%$ may be obtained. The importance of the operating conditions and water chemistry of filtered suspensions have been highlighted by several studies. Thus, Wu et al. [16] emphasized the importance of TMP on NPs retention showing that quantum dots of $1.5 \mathrm{~nm}, 2.2 \mathrm{~nm}$ and $3.8 \mathrm{~nm}$ are respectively retained at about $75 \%, 90 \%$ and $100 \%$ under a TMP of 0.6 bar against about $15 \%, 20 \%$ and $68 \%$ under 2 bar by a $30 \mathrm{kDa}$ membrane. The duration of the filtration cycle may have an influence on the retention rate (RR) due to the evolution of retention with the fouling of the membrane (charge effect, pore blocking) [18-20]. Concerning the suspension chemistry, some studies showed that the presence of a salinity in the feed suspension leads to an increase in the retention of NPs by UF membranes. Lee et al. [21] showed that when the particle to pore diameter ratio is inferior to 1 , the effect of ionic strength is important for the retention efficiency. In the same way, Jassby et al. [22] studied the influence of the presence of different cations and their concentrations on retention of fullerene NPs by $20 \mathrm{~nm}$ UF membrane. They showed that the presence of salt leads to an aggregation of NPs. They studied the influence of TMP on retention with presence of salts and advanced the following assumption: when di-valent ions are added, they act as bridge between the aggregates formed and may be deformed under higher pressure tested $(0.3 \mathrm{bar})$ to penetrate in the membrane without being broken. However, when monovalent ions are in suspension, aggregates are formed but they will be broken if a pressure of $0.3 \mathrm{bar}$ is applied, leading to a passage of fullerene through the membrane. In the same way, Chae et al. [23] showed that, during filtration of hydroxylated fullerene NPs $\left(\mathrm{nC}_{60}(\mathrm{OH})_{24}\right)$ by $30 \mathrm{~nm}$ UF membrane, the presence of $\mathrm{NaCl}$ with concentration increasing from 0 to $1.5 \mathrm{~mol} \mathrm{~L}^{-1}$ leads to an increasing of the size of NPs from $185 \mathrm{~nm}$ to $1405 \mathrm{~nm}$. The NPs retention rate is improved by this increase in size, but its value does not exceed $60 \%$. The authors also studied the effects of natural organic matter (NOM) on the NPs removal efficiency and showed that the adding of NOM leads to an increase of NPs stability and thus, a decrease of the retention by the membrane. However, it is important to consider the material of NPs. In fact, all NPs materials do not have the same behavior in identical operating conditions. Olabarrieta et al. [24] argues that for an adding of $2 \mathrm{mmol} \mathrm{L}^{-1}$ of $\mathrm{NaCl}$ in ultrapure water, retention efficiency of $\mathrm{CeO}_{2}$ by UF membrane was decreased while retention efficiency of $\mathrm{Ag}$ was increased. Moreover, the material of the membrane used presents an influence on NPs retention with possible charge effect between NPs and membrane materials $[25,26]$.

The operating conditions, the water chemistry, the NPs and membrane materials thus have an influence on the retention of the NPs but also on the membrane fouling. First, the number of NPs blocked at the membrane may be affected by these parameters. Jassby et al. [22] showed that, with presence of salt, the NPs penetrate and stay blocked in membrane material instead of passing through the membrane and be recovered in the permeate. Moreover, the location of foulants may be affected. Wu et al. [16] showed, thanks to establishment of NPs penetration profile in fouled membranes, that the NPs penetration into the material varies with TMP. The charge effects between membrane material, NPs material and compounds present in water may also lead to changes in NPs penetration, their blocking in the membrane and may so impact the proportion of NPs recovered in permeate and retentate.

Aims of this study are to clearly identify the retention potential of multichannel hollow fiber UF membranes towards NPs with sizes close to and smaller than membrane pore size, filtered individually or together with or without salt. A precise and reliable location of NPs in membrane material at the end of the filtration allowed to identify fouling mechanisms operating during the filtration. It was also possible to determine the influence of simultaneous filtration of different NPs sizes and the presence of salts on NPs retention and fouling establishment and to put forward the charge effects between NPs and membrane. 


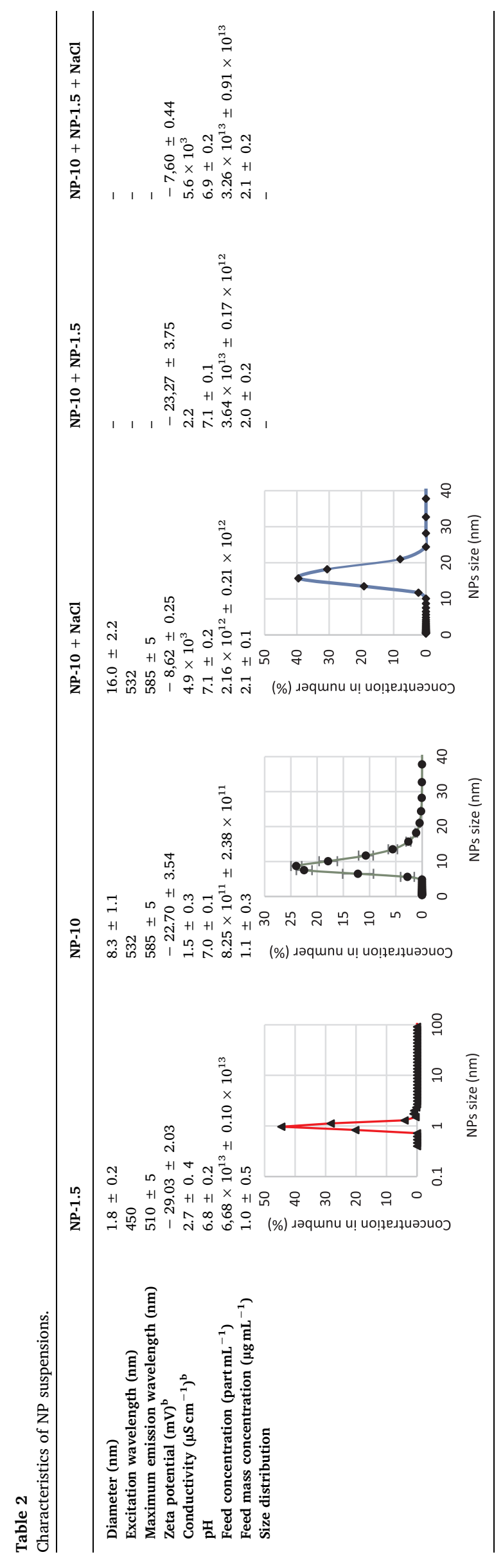

\section{Materials and methods}

\subsection{Membranes}

Ultrafiltration membrane used in this study is multichannel (7 channels) organic hollow fiber (ALTEON ${ }^{\mathrm{TM}}$ I, SUEZ aquasource ${ }^{\circ}$, France) made with hydrophilic polyethersulfone (PES) and used for drinking water production. Its average nominal pore size is $20 \mathrm{~nm}$ (MWCO = $200 \mathrm{kDa}$ ) [18]. At neutral $\mathrm{pH}$ (under filtration conditions $\mathrm{pH}=$ $7 \pm 0.5$ ), the membrane zeta potential is about $-22 \mathrm{mV}$ (constructor data). It is, therefore, of the same sign (charge) and about the same intensity as the NPs suspensions (Table 2). This data indicates a low probability of NPs adsorption due to the repulsive forces between particles and membrane material.

\subsection{Nanoparticles}

Two sizes of NPs have been used: one smaller than the membrane pore size $(1.5 \mathrm{~nm})$ and one close to the membrane pore size $(10 \mathrm{~nm})$, called NP-1.5 and NP-10 respectively. Smallest NPs, NP-1.5, are hydrophilic CdTe quantum dots coated with a proprietary mixture of lowmolecular weight thiocarboxylic acid (PlasmaChem GmbH, Germany). The NP-10 are spherical silica NPs (Sicastar Red-F, Micromod Partikeltechnologie GmbH, Germany). They are labeled with rhodamine, a fluorescent dye, covalently bound in the silica matrix. Shape of NP-10 was visualized by Scanning Electron Microscopy (SEM) in a previous study [18]. NP-10 have hydrophilic surface with Si-OH end groups. Size distributions of both NPs were obtained with Zetasizer Nano S (Malvern, England). Average sizes and size distributions of each monodisperse NP suspensions are presented in in Table 2. Size distributions of NPs in mixtures (NP-1.5 + NP-10) were measured thanks to the Zetasizer Nano S. The absorption spectra of both NPs were obtained with a spectrophotometer (UV-VIS photoLab ${ }^{\circledR}$ 6600, WTW $\mathrm{GmbH}$, Germany). Zeta potential of NPs suspensions were measured with a Zetasizer Nano ZS (Malvern, England). Neutral pH was checked for the zeta potential measurement. These sizes of NPs, smaller than and close to membrane pore size, have been chosen to visualize an eventual evolution of retention during the filtration run.

\subsection{NP concentration measurement}

NPs concentrations were measured with a fluorimeter (Jenway 6300, Bibby Scientific Limited, UK). Calibration curves linking the fluorescence intensity returned to the particle concentration per milliliter have been realized for both NP. The concentration error for fluorimeter has been evaluated at $2.2 \%$ by experiment. In order to cover a maximum range of NPs concentration without modification of samples, calibration curves were realized for different gain adjustments of the fluorimeter. Thus, more than five calibration curves were realized for each NPs allowed to measuring concentrations from $1.10^{10}$ to $1.10^{14}$ part.mL ${ }^{-1}$. Excitation and emission filters used to detect NP-1.5 and NP-10 are not the same (Table 2), allowing the differentiation of the NPs in mixtures. A verification of the variation of fluorescent intensity emitted by the considered NPs applying appropriate fluorescent filters with the adding of the second NPs size used was carried out. The polydispersity of suspension showed no influence on the fluorescent signal recovered. Thus, in a mixture, the fluorimeter makes it possible to obtain the concentration of each of the both NPs sizes. Similarly, the addition of $\mathrm{NaCl}$ in the NPs suspension did not show any influence on the fluorescence emission of the NP suspensions.

\subsection{Filtration experiments}

"Ideal suspensions" of each NP size, composed of NPs dispersed in ultrapure water filtered by UF membrane $\left(\right.$ ALTEON $^{\mathrm{TM}} \mathrm{I}$ ), combination of both NP sizes (in the same concentration used in individual 
suspensions) and NPs suspensions with the adding of $50 \mathrm{mmol} \mathrm{L}^{-1}$ of $\mathrm{NaCl}$ were filtered under different TMP (from 0.2 to $0.4 \mathrm{bar}$ ) until a Volume Concentration Factor (VCF) of 200. UF membranes tested in this study are used in drinking water production from surface water which justifies the chosen operating conditions: (a). the fresh water of surface water used to produce drinking water generally contains less than $1 \mathrm{~g} \mathrm{~L}^{-1}$ of dissolved salts, which represent about $43.5 \mathrm{mmol} \mathrm{L}^{-1}$ of dissolved salt, (b)the drinking water production is generally realized under low pressure between 0.2 and 0.4 bar and filtration cycles may be short (VCF of 200). All characteristics of suspensions filtered are presented in the Table 2.

Feed suspensions were disposed in a pressurized tank connected to the filtration module. The filtration module was made by potting one multichannel membrane into an external shell (PVC) in an epoxy plug at each side of the module. A new module and a new membrane were used for each experiment. Before the NPs suspension filtration, the membrane was flushed with Milli-Q water (conductivity of 0.8 $\mu \mathrm{S} . \mathrm{cm}^{-1}$ ) under a TMP of 1 bar to remove glycerin used for the membrane preservation. Filtration was carried out in dead-end mode and the mass of the permeate collected was recorded by an electronic balance $(\Delta \mathrm{m}= \pm 0.01 \mathrm{~g})$ over the time as well as the TMP which was followed with a digital manometer with record function (LEO Record, KELLER, Swiss). All filtration runs were carried out at room temperature $\left(20^{\circ} \mathrm{C} \pm 2{ }^{\circ} \mathrm{C}\right)$. At the end of the filtration, the retentate contained in fiber channels was recovered by capillarity, the module was disconnected and the membrane was recovered for a microscopic autopsy.

\subsection{Data of interest}

Permeability of the membrane over the filtration experiment was evaluated following the permeate mass collected versus the filtration time. The follow-up of the permeate flux allowed to determine potential fouling mechanisms operating during the NPs filtration with the application of Hermia models $[18,27,28]$. This permeate was recovered in different samples and each of them was analyzed to determine NPs concentration over the time. A theoretical retention rate in function of the filtration time was calculated thanks to these concentrations. In fact, retentate concentration was estimated at each time $t$ by mass balance (for a permeate quality) assuming all NPs engaged in the filtration not recovered in the permeate compose the retentate. So theoretical retention rate was calculated following Eq. (1):

$R R_{t h}=1-\frac{N_{p(t)}}{N_{r(t)}}=1-\frac{C_{p(t)} V_{p(t)}}{\left(C_{f} V_{f(t)}\right)-\left(\sum C_{p(t)} V_{p(t)}\right)}$

where $N_{p(t)}, N_{r(t)}$ are the number of NP respectively found in the permeate and the retentate at the considered time; $\mathrm{C}_{p(t)}$ is the permeate concentration in part. $\mathrm{mL}^{-1}$ at the time considered; $\mathrm{C}_{\mathrm{f}}$ the feed concentration in part.mL ${ }^{-1} ; \mathrm{V}_{\mathrm{f}(\mathrm{t})}$ is the feed volume engaged in the filtration at the considered time (sum of permeate and retentate volume) and $\mathrm{V}_{\mathrm{p}(\mathrm{t})}$ is the permeate volume collected at the same time. Thereby, the term $\left(C_{f} V_{f(t)}\right)-\left(\sum C_{p(t)} V_{p(t)}\right)$ describes the number of NP engaged in the filtration minus the number of NP recovered in the permeate at the considered time, illustrating the number of NP retained by the membrane and composing the retentate.

At the end of the filtration, the concentration of the retentate collected was analyzed by fluorimetry and a final experimental retention rate has been determined considering global concentration of each permeate collected and this final retentate concentration measured. The difference between theoretical RR and experimental RR reflects the number of NPs stayed blocked at the membrane. The theoretical RR is estimated: it is considered that all NPs filtered are recovered in the retentate volume (i.e. retentate concentration is calculated by mass balance) and in the permeate side while the experimental RR takes into account the real concentrations measured in the retentive volume and thus allows by difference to identify the NPs quantity blocked at the membrane. Thus, the quantity of NPs blocked at the membrane was calculated (in number) from the concentrations of each fluxes collected at the end of the filtration.

\subsection{Membrane autopsy by Confocal Laser Scanning Microscopy (CLSM)}

At the end of the filtration, membrane was recovered and dried in a desiccator with anhydrous calcium sulfate. Then, it was cut after freezing in liquid nitrogen to limit the deformation of the membrane material. Samples of fouled membrane obtained were analyzed by Confocal Laser Scanning Microscopy (CLSM, TCS SP5, Leica Microsystems CMS GmbH, Germany) [18]. For each filtration experiment, the membrane was analyzed at different lengths on its section. More than 50 measurements were realized on each fouled membrane. In function of the experiment conducted, different scans were realized to identify membrane, NP-1.5 and NP-10. In fact, CLSM allows to detect individually each component in function of the measured wavelengths ranges (fluorescent signals of NPs of différent size and reflected light by the membrane structure). A visible scan using an excitation laser of $532 \mathrm{~nm}$, the separator RT 30/70 and recovering the emitted signal from 530 to $535 \mathrm{~nm}$ allowed to visualize the membrane. Fluorescent scan to localize NP-1.5 was realized using an excitation laser of $405 \mathrm{~nm}$, the separator DD 405/532 (cutting the excitation wavelength) and recovering the emitted signal from 505 to $515 \mathrm{~nm}$. Finally, a second fluorescent scan allowed to identify NP-10 was realized using the $532 \mathrm{~nm}$ excitation laser, the DD 405/532 separator and recovering the emitted signal from 575 to $585 \mathrm{~nm}$.

\section{Results and discussion}

\subsection{Monodisperse suspensions (NP-10 or NP 1,5)}

Filtration of ideal and monodisperse NP-10 suspension (NP-10 dispersed in ultrafiltered ultrapure water / NP-10) was conducted until a VCF of 200 under $0.2,0.3$ and 0.4 bar. The experimental retention rate of NP-10 found for each experiment was superior or equal to $99 \%$, showing no effect of TMP on NP-10 retention. The follow-up of the theoretical retention rate over the filtration, presented in Fig. 1-a), shows a quick increase of NP-10 retention during the filtration to reach a theoretical RR superior to $99 \%$ once a VCF of 20 is achieved. The variation of TMP does not show significant effect on theoretical RR. The amount of NP-10 blocked at the membrane has been evaluated by comparison between the theoretical retentate estimated by mass balance and the concentration of collected retentate. The location of NP-10 was made at the end of the filtration. Fig. 1-b) illustrates the amount (in number) of NP-10 recovered in permeate, in the retentate and blocked at the membrane at the end of the filtration. The fraction blocked "at" the membrane is defined like the number of NPs stayed blocked on membrane surface and/or in membrane material at the end of the experiment and which is not recovered in the retentate or in the permeate. It can be observed that, whatever the TMP applied, the majority of NP10 is recovered in the retentate, which is in agreement with the high RR observed. Autopsy of membrane fouled by NP-10 have been realized by CLSM and showed that NP-10 blocked at the membrane are located on membrane surface and in the membrane skin (until a depth of about $50 \mu \mathrm{m})$. The assumption, which can be made, is that during the first step of the filtration, a pore blocking carried out in the membrane skin, and then, a deposit on membrane surface is formed. The application of Hermia model confirms this assumption showing a correlation coefficient superior to 0.9 for both models successively (standard blocking followed by cake filtration). The TMP has an effect on duration of each fouling mechanism reducing the duration of pore blocking model but not on the fouling mechanism. The consequence on CLSM images is an increase of the normalized intensity of the pic at the membrane surface comparatively to the fluorescent signal normalized found in the membrane skin reflecting a ratio NP-10 deposed on membrane surface/NP- 

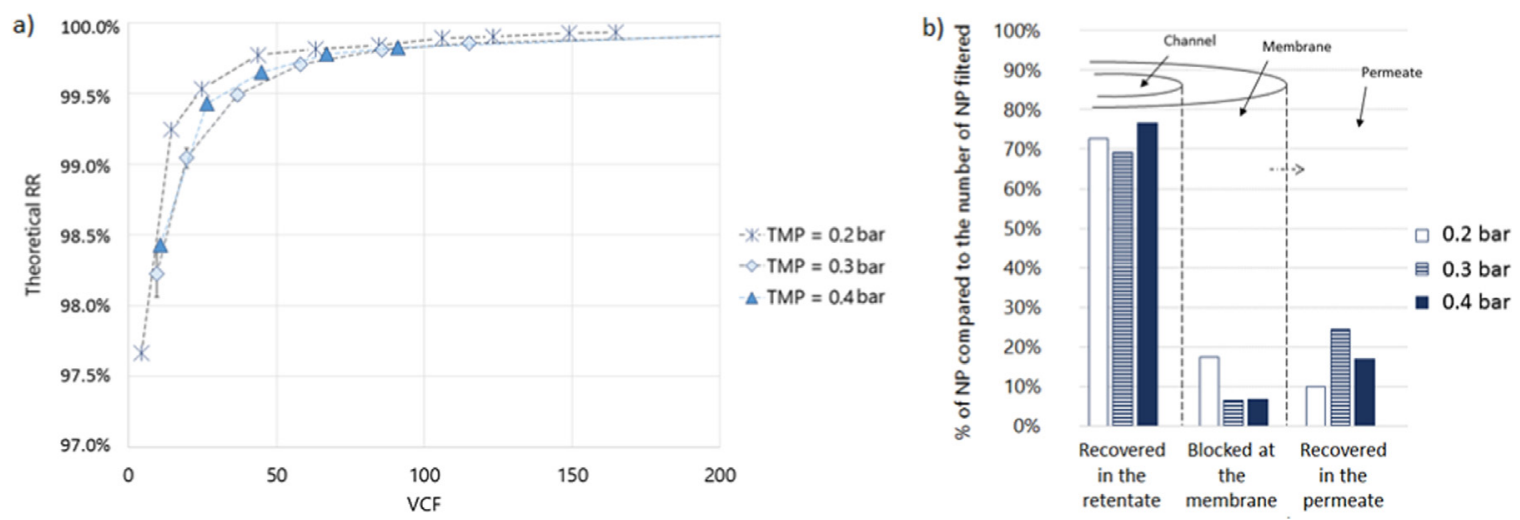

Fig. 1. Theoretical retention rate of NP-10 as a function of VCF for different TMP (a)) and recovery of NP-10 at the end of their filtration for different TMP (b)) (monodisperse NP-10 suspension).

a)
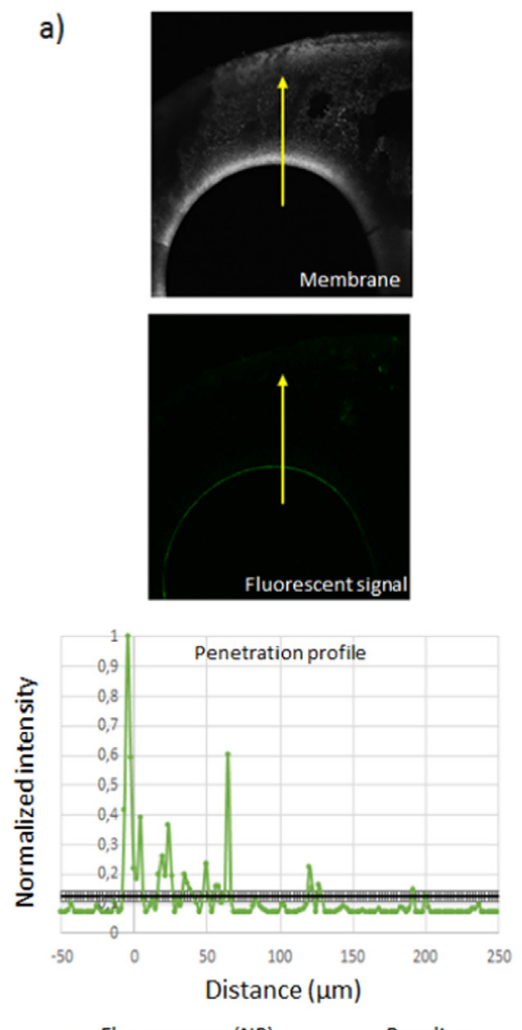

- Fluorescence (NP) _ Baseline b)
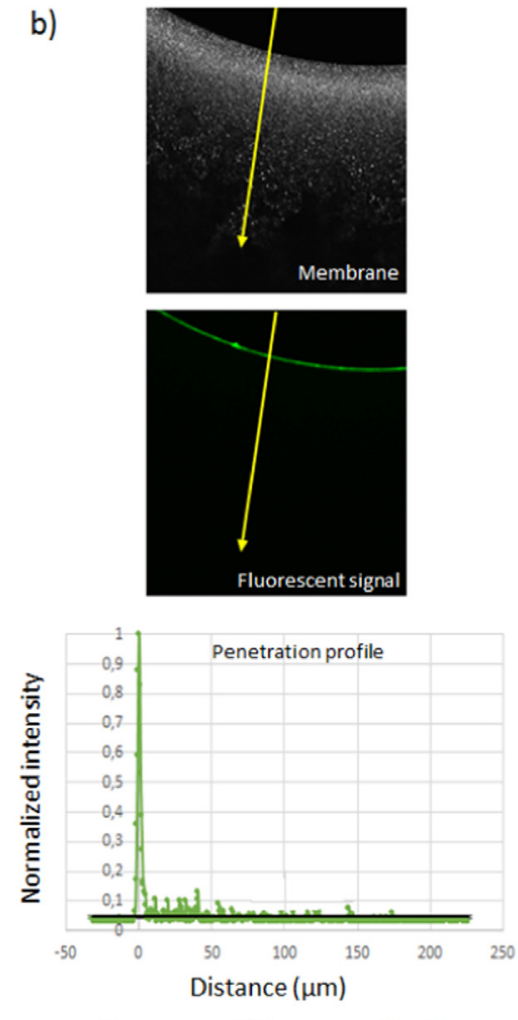

- Fluorescence (NP) - Baseline c)
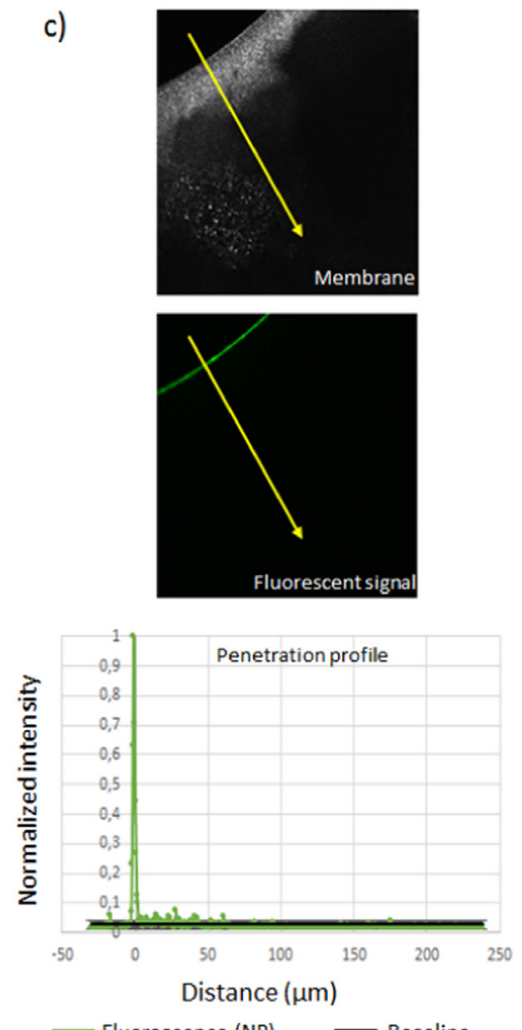

- Fluorescence (NP) - Baseline

Fig. 2. Penetration profiles of NP-10 in membrane after filtration for different TMP a) 0.2 , b) 0.3 and c) 0.4 bar (monodisperse NP-10 suspension). The baseline correspond to the evaluated noise level.

10 in membrane skin increasing (Fig. 2).

Filtration of ideal and monodisperse NP-1.5 suspension was also conducted until a VCF of 200 under $0.2,0.3$ and 0.4 bar. The experimental retention rate of NP-1.5 obtained at the end of the filtration is dependent of TMP applied during the filtration. The increase of TMP reduces the NP-1.5 retention rate from 87.1 to 84.3 and 77.7 for filtration conducted under $0.2,0.3$ and 0.4 bar respectively. Under 0.4 bar, the NP-1.5 are pushed through the membrane reducing the theoretical RR over the filtration like it is shown in Fig. 3-a). The decrease of retention rate leads to an increase of the NP-1.5 quantity recovered in the permeate as it is shown in Fig. 3-b). A low amount of NP1.5 is recovered in the collected retentate, which shows that NP-1.5 are blocked in membrane material. The fouling of the membrane by NP-1.5 leads to an increase of retention rate over the filtration. Autopsy of the membrane allowed a location of NP-1.5 and showed a retention in the entire depth of the membrane material. Application of Hermia models' laws to experimental data shows a standard pore blocking followed by a cake filtration. However, the pore blocking duration is longer than the one observed for NP-10. The increase of TMP do not really affect the NP-1.5 quantity recovered in the retentate but the quantity blocked in the membrane (Fig. 3-b)). The CLSM images have confirmed these results. In fact, as shown by Fig. 4, the increase of TMP greatly reduced the quantity of NP-1.5 fluorescent signal found in membrane. At higher TMP, a flushing of the membrane is made by filtered water. The fouling formed by NP-1.5 arrived at the membrane modify the selectivity of this one. The retention of NP-1.5 become more efficient and the water, which pass through the membrane, contains less NPs. This purified water may carry the particles during its passage and flush the membrane. 
a)

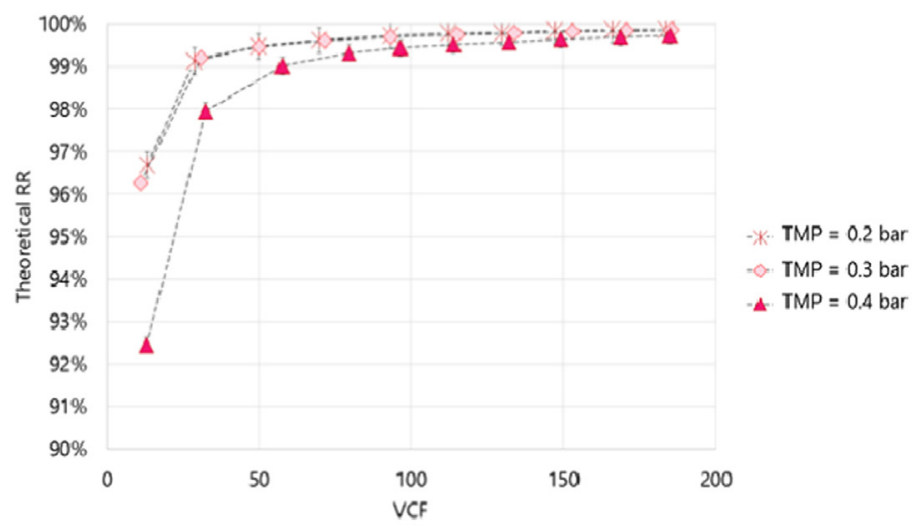

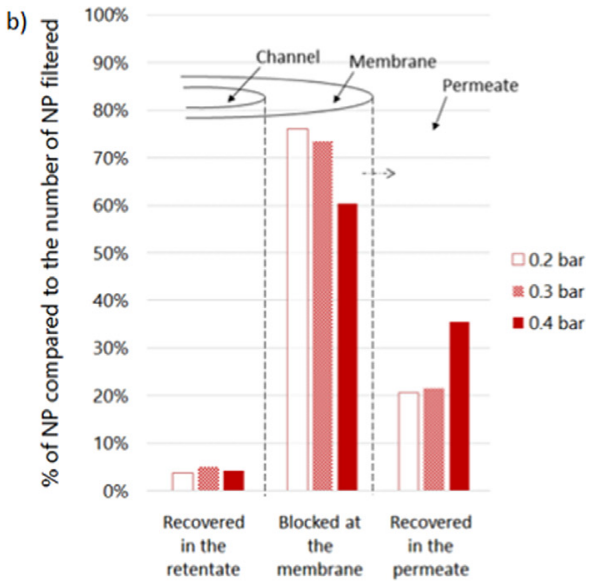

Fig. 3. Theoretical retention rate of NP-1.5 as a function of VCF for different TMP (a)) and recovery of NP-1.5 at the end of their filtration for different TMP (b)) (monodisperse NP-1.5 suspension).

a)
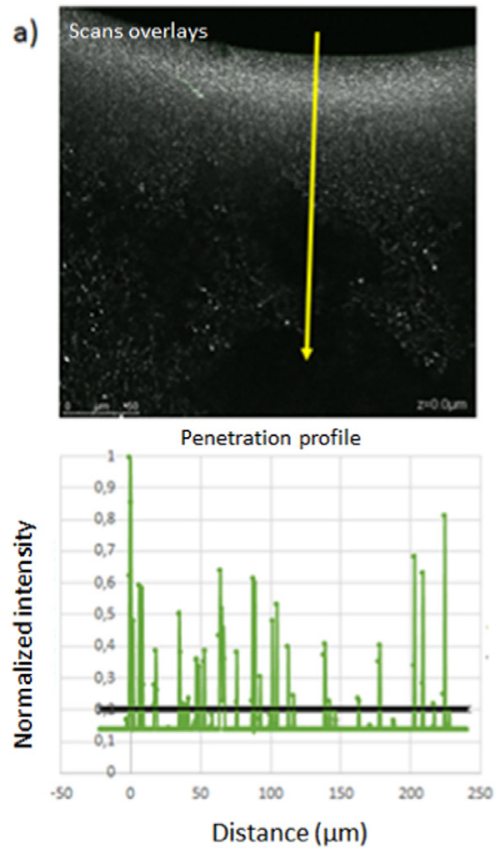

- Fluorescence (NP) - Baseline b)
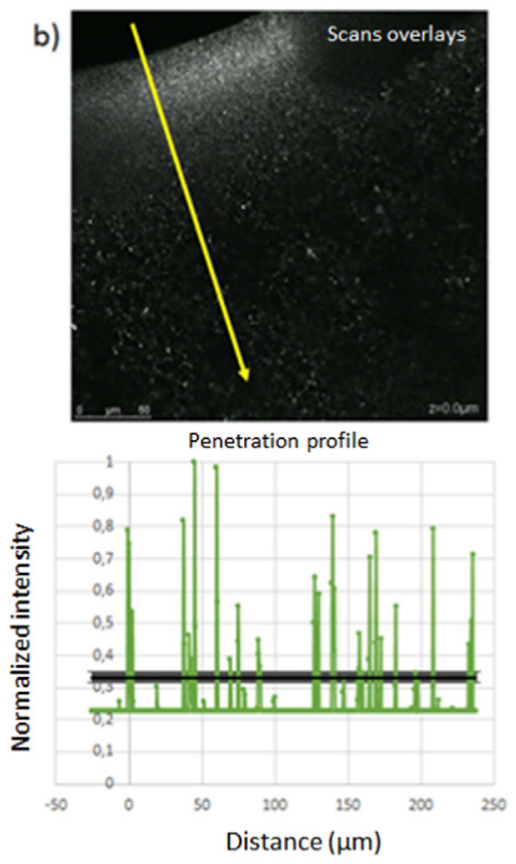

c)
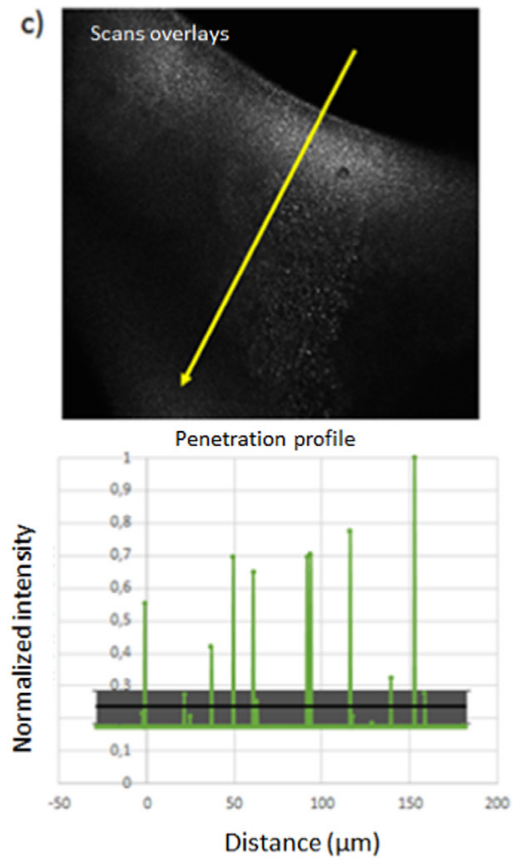

- Fluorescence (NP) — Baseline

Fig. 4. Penetration profiles of NP-1.5 in membrane after filtration for different TMP a) $0.2, b) 0.3$ and c) 0.4 bar (monodisperse NP-1.5 suspension). The baseline correspond to the evaluated noise level.

a)

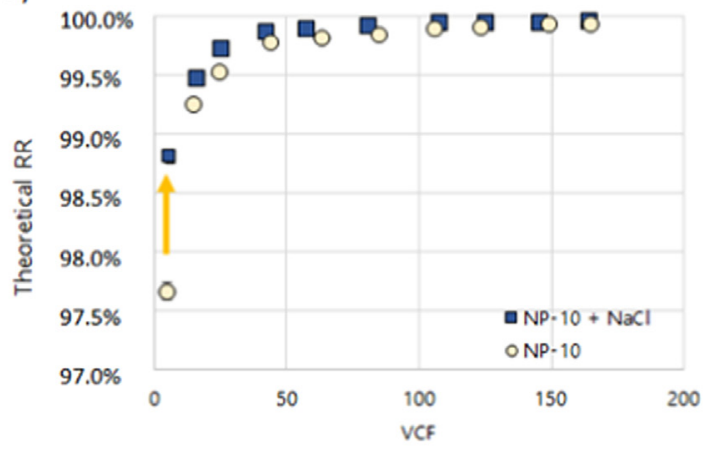

b)

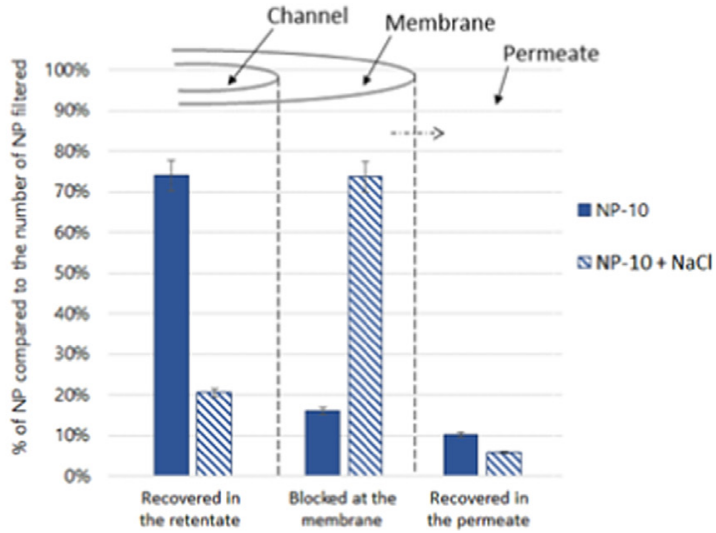

Fig. 5. Theoretical retention rate as a function of VCF for different salinity (a)) and recovery of NP-10 at the end of their filtration under TMP $=0.2$ bar and until VCF $=200$ as a function of the salinity (monodisperse NP-10). 
a)

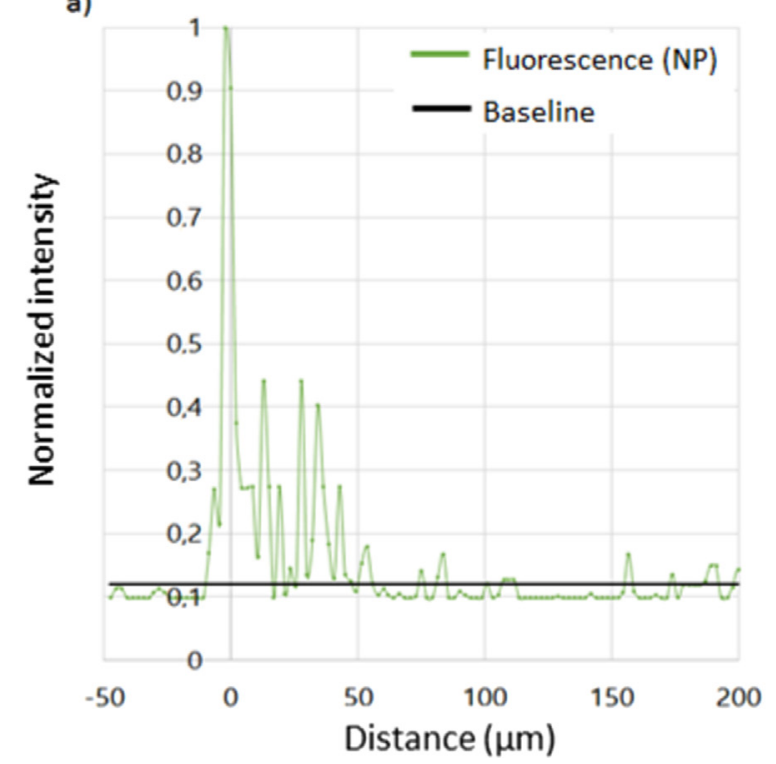

b)

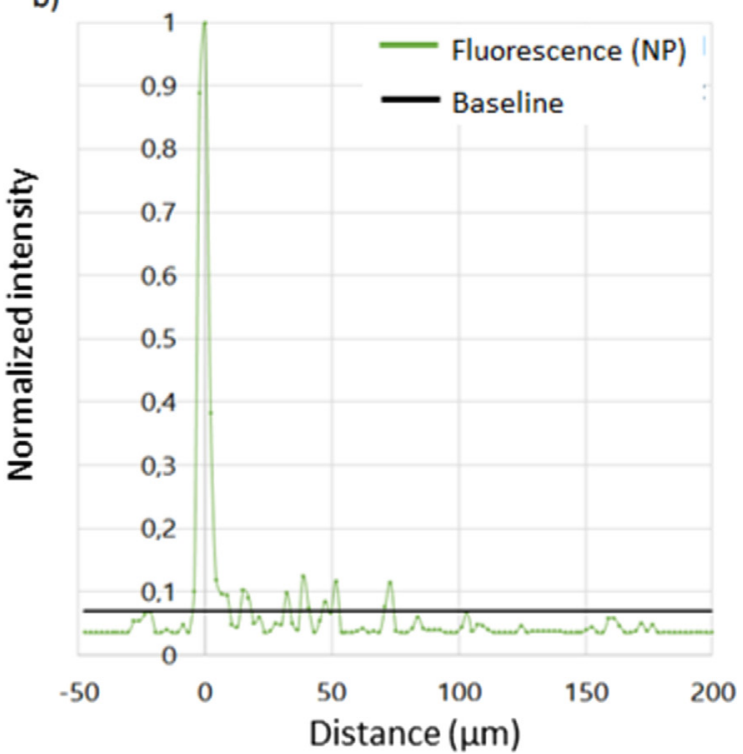

Fig. 6. Penetration profiles of NP-10 in membrane after their filtration a) without salt and b) with the adding of $50 \mathrm{mmol} \mathrm{L}^{-1}$ of NaCl (monodisperse NP-10, TMP $=0.2 \mathrm{bar}, \mathrm{VCF}=200$ ).

a)

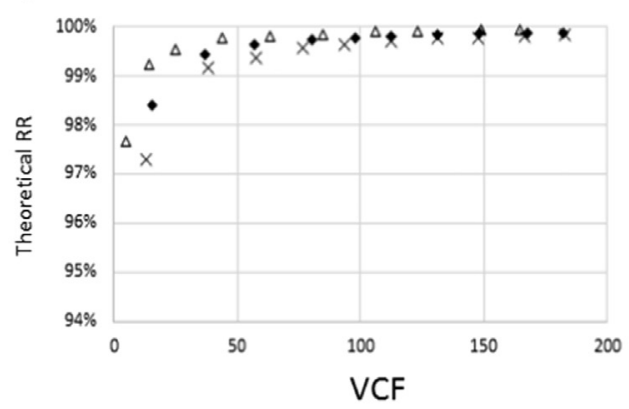

b)

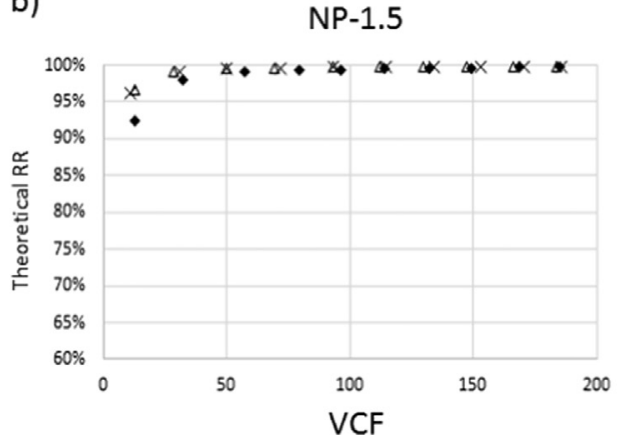

$\triangle 0,2$ bar $\times 0,3$ bar - 0,4 bar $\triangle 0,2$ bar $\times 0,3$ bar - 0,4 bar
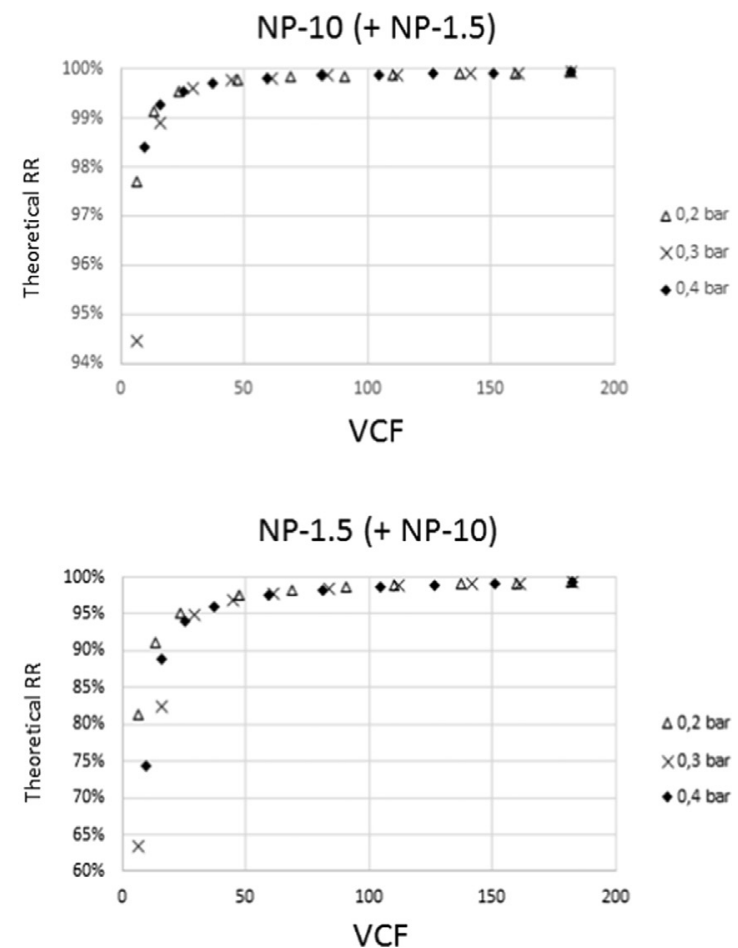

Fig. 7. Theoretical retention rate of a) NP-10 and b) NP-1.5 as a function of VCF for different TMP (left: monodisperse suspension; right: polydisperse suspension).

\subsection{Influence of salinity}

The influence of the salinity of the feed suspension on the retention of NP-10 was investigated. The NP-10 feed suspensions were prepared with the adding of $50 \mathrm{mmol} \mathrm{L}^{-1}$ of $\mathrm{NaCl}$. Influence of the salinity on retention rate, number of NP-10 blocked at the membrane and location of fouling have been studied. The presence of salt in the feed suspension substantially improves the theoretical RR of NP-10 observed during the filtration (Fig. 5-a)). However, the evolution of this one follows the same trend and an increase of theoretical RR during filtration is observed. It appears that more NP-10 are retained at the beginning of the filtration. The size distribution of the suspension has been analyzed with Zetasizer and the average size was doubled showing aggregation of NP-10 (Table 2). This higher average size in presence of salt explains the increase of NP-10 blocked by the membrane. In fact, Fig. 5-b) shows that the quantity of NP-10 recovered in the retentate at the end of the filtration is greatly reduced when $\mathrm{NaCl}$ is adding in feed suspension reflecting the increase of quantity blocked by the membrane. The presence of salts had no effect on the final RR calculated with the concentration of collected retentate which stay superior to $99 \%$. Tarabara et al. [29] have shown that the organization of particles deposition layers on the membrane surface depends on the forces acting on these particles. Forces between particles therefore strongly depend on the chemistry of the suspension and therefore the presence of salt. The ionic 
a)

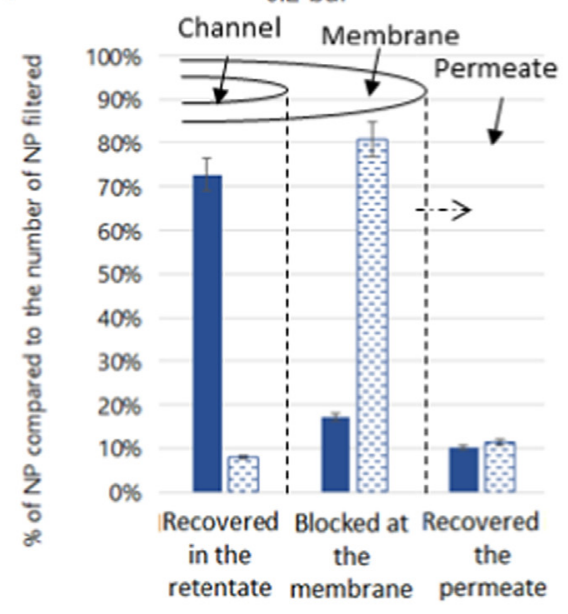

nNP-10 $\quad$ N NP-10 (+NP-1.5) b)

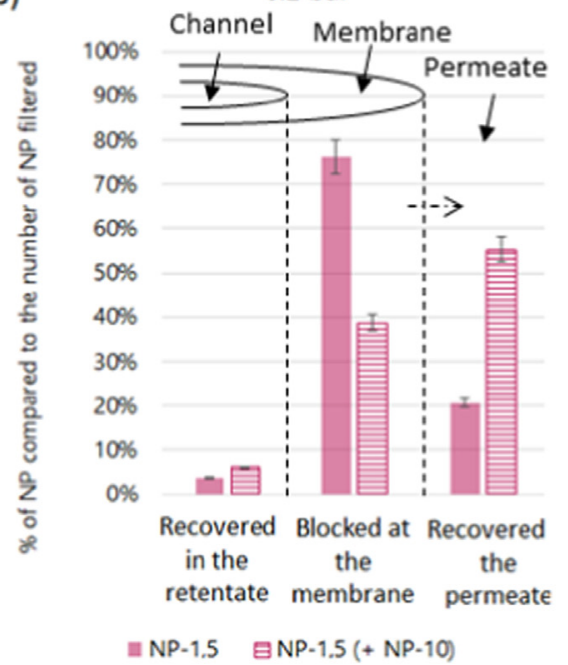

0.3 bar

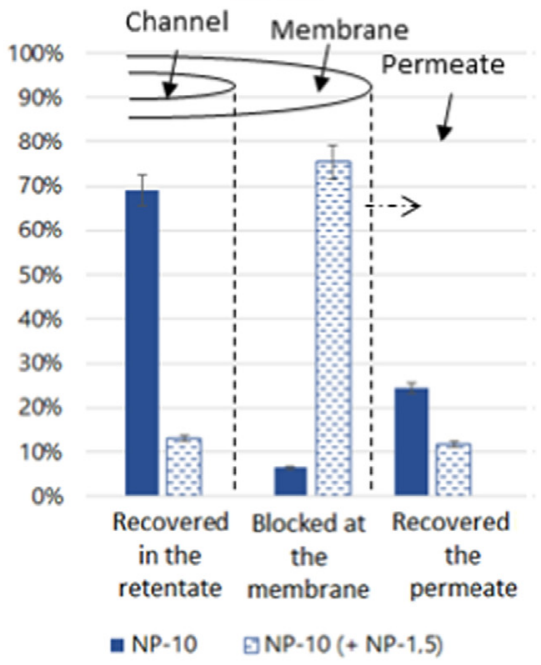

0.3 bar

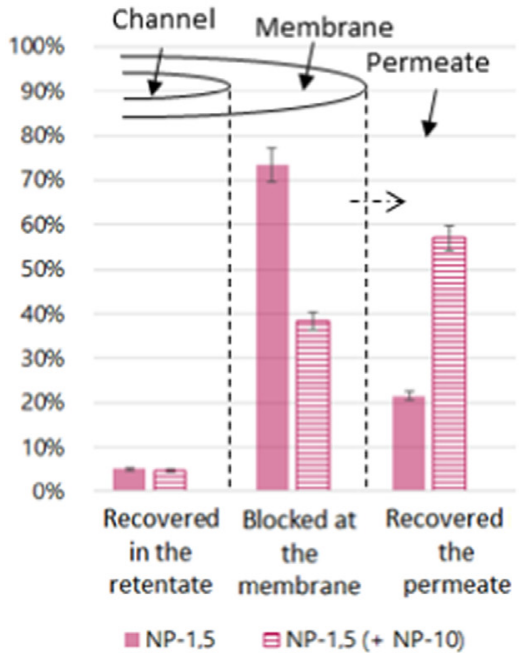

0.4 bar

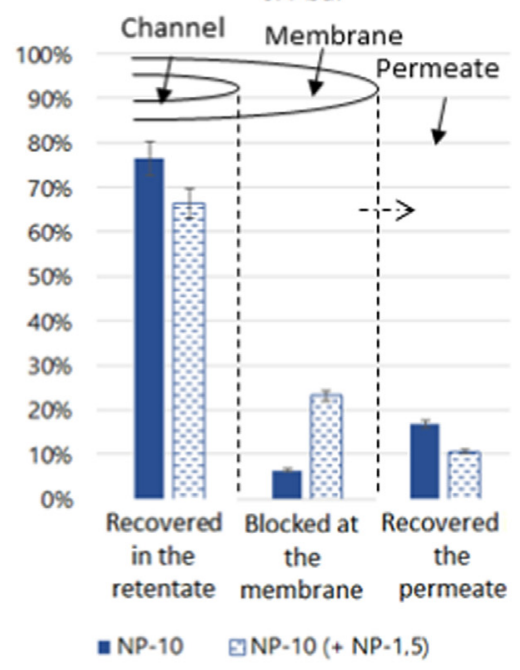

0.4 bar

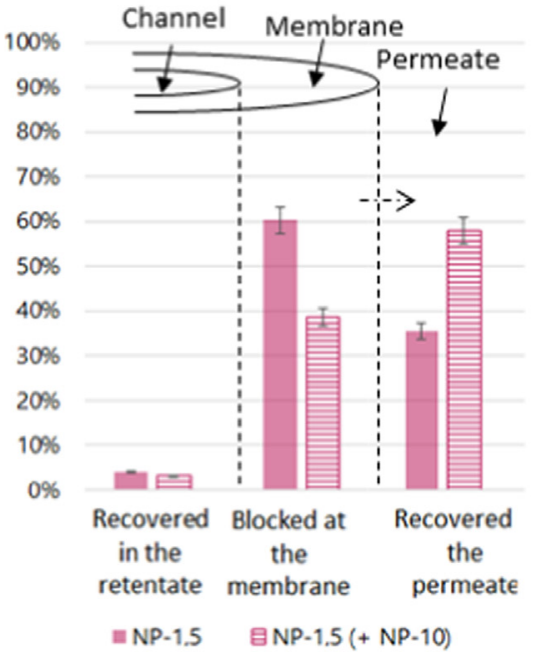

Fig. 8. Recovery of a) NP-10 and b) NP-1.5 at the end of their filtration for different TMP as a function of the polydispersity $(\mathrm{VCF}=200)$.

strength of a suspension determines the potential for electrostatic repulsions between particles. An increase in the ionic strength and/or a decrease in the surface potential of the particles causes a destabilization of the particulate suspension which can lead to a NP-NP attraction. Thus, when the ionic strength is greater, the NP-NP repulsions and/or the NP-membrane repulsions may decrease due to a reduction in the thickness of the electric double layer. As it is shown in Table 2, the NPs average size is increased and zeta potential is considerably decreased by $\mathrm{NaCl}$ addition. This variation justifies the modification of repulsion between NP-NP and NP-membrane. The decrease of NP-membrane repulsions may reflect the increase in the number of NPs blocked on and/ or in the membrane material. In order to validate this assumption, a visualization of the fouled membranes by CLSM was carried out and the NP-10 penetration profiles were defined. The penetration profiles of NP-10 after their UF without and with $\mathrm{NaCl}$ under 0.2 bar until a VCF of 200 were compared (Fig. 6). In both case, NP-10 are present in the skin of the membrane and on its surface. The profiles obtained confirm the greater relative presence of NP-10 on the surface of the membrane. The difference of normalized intensity between the deposition on the surface and the NP in the skin of the membrane is greater in the case of the filtration with salt. However, as the number of NP-10 blocked at the membrane is increased in presence of salt for the same operating conditions applied, these profiles show that the blocking of NP-10 is preferentially increased in the NP deposit on the membrane surface in presence of salt. Thus, the location of NP-10 blocked at the membrane is not modified but the number of NPs remained blocked is increased and the ratio NP-10 on surface/NP-10 in membrane skin is increased too. For the Hermia modeling of experimental results, the first part of the filtration (from the beginning to $60 \mathrm{~mL}$ of permeate collected) seems to follow the behavior of a complete blocking of membrane pores. This result can be explained by the increase of the NP average size. This one comes close to membrane pore size. This observation can also explain the greater number of NP-10 blocked on surface compared to number stopped in membrane skin. Finally, for NP-10 whose size is near membrane pore size, the addition of salinity decreases the NP-NP and NP-membrane repulsions, reflecting a greater accumulation of NP-10 at the membrane surface (CLSM data), a lower recovery rate and a slightly different retention rate (slightly improved theoretical RR and experimental RR always higher than 99\%). The amount of NP-10 blocked is larger with presence of $\mathrm{NaCl}$ but it consists of NPs agglomerates, as shown by size measurements as a function of salinity. These agglomerates preferentially remain on the membrane surface. Compared to the filtration of an ideal suspension, the presence of salt modifies the mechanisms of fouling establishment. The increasing of the average size of NP-10 leads to faster pore blocking followed by a deposit at the membrane surface. 


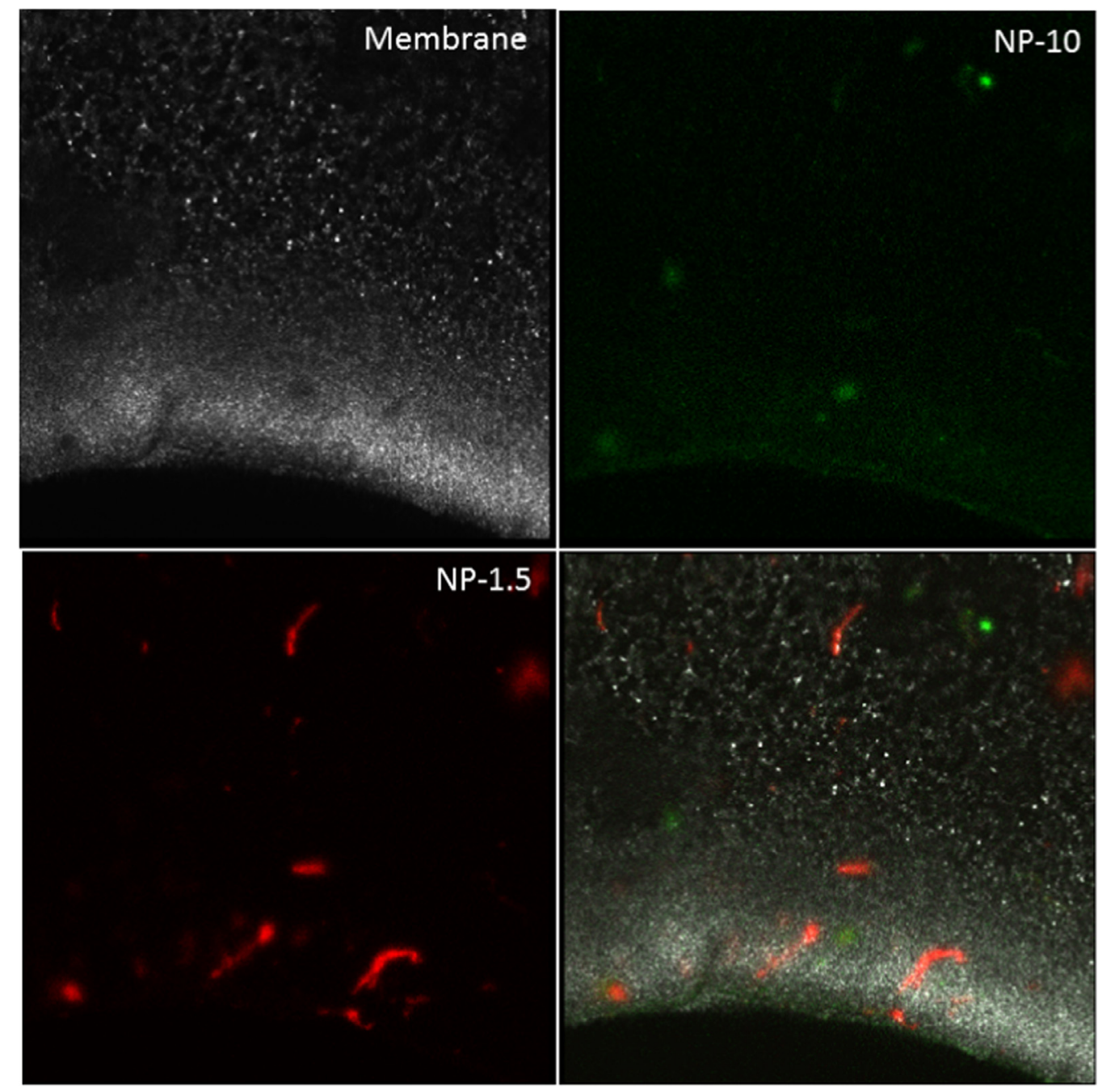

Fig. 9. Scans obtained by CLSM for visualization of membrane microstructure, NP-10 and NP-1.5 and superimposition of these 3 scans (bottom right) for the visualization of membrane fouled by polydisperse NPs suspension and the identification of NP-1.5 clusters (TMP $=0.2 \mathrm{bar}, \mathrm{VCF}=200$ ).
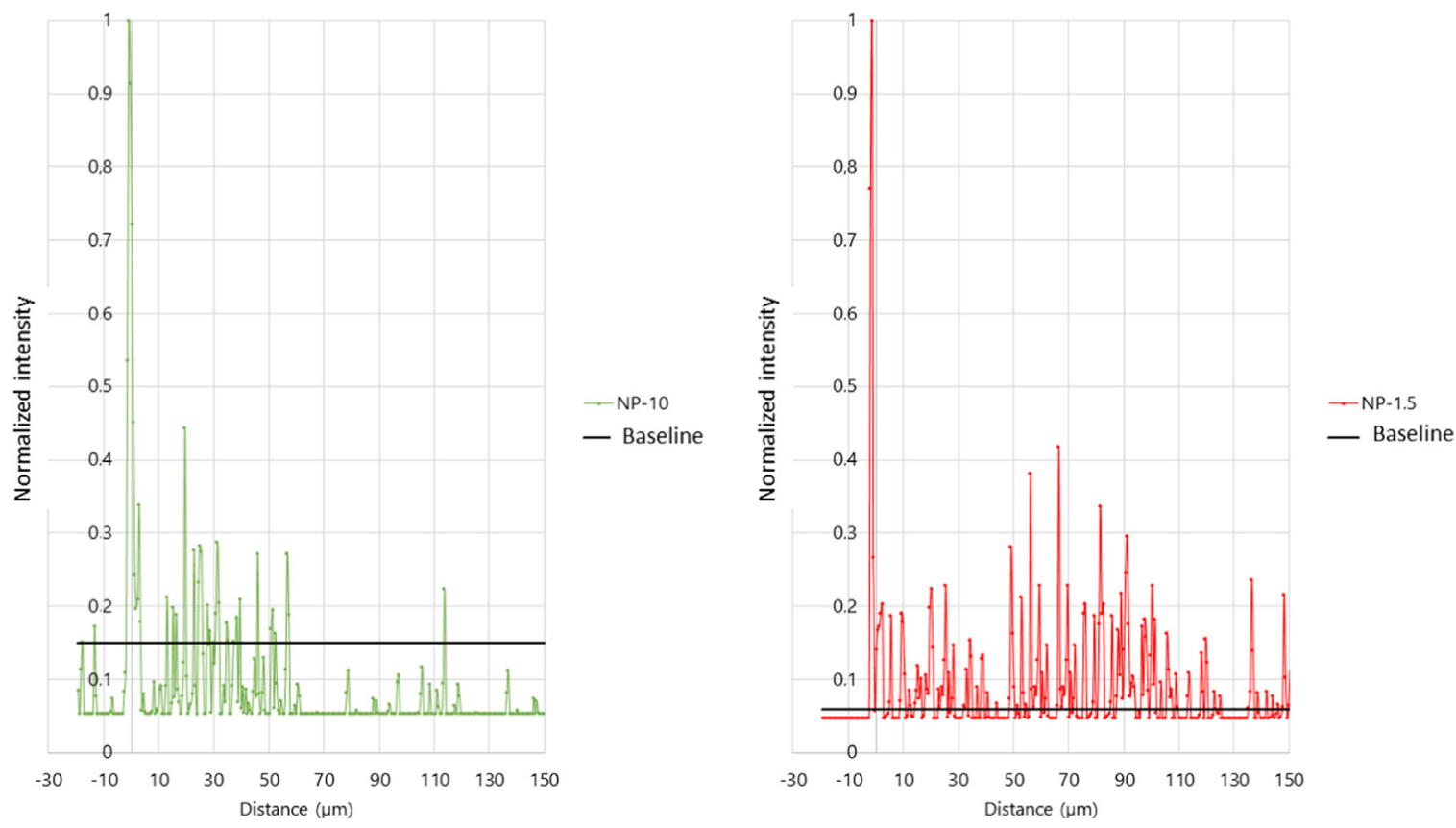

Fig. 10. Penetration profiles of NP-10 and NP-1.5 in membrane after their filtrations in polydisperse suspension (TMP $=0.2$ bar, VCF $=200$ ). 
a)

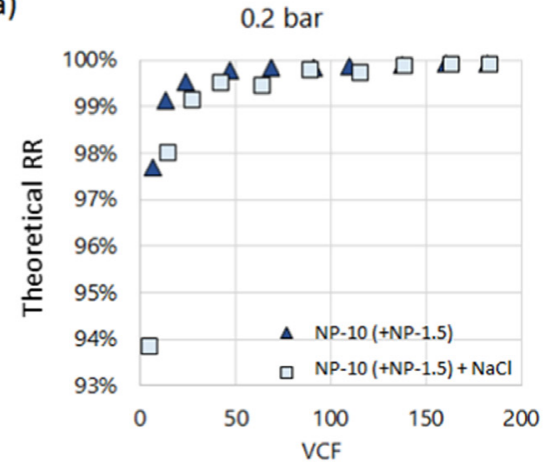

b)

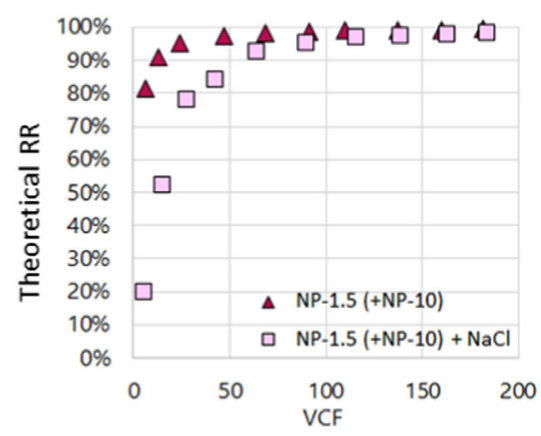

$0.3 \mathrm{bar}$

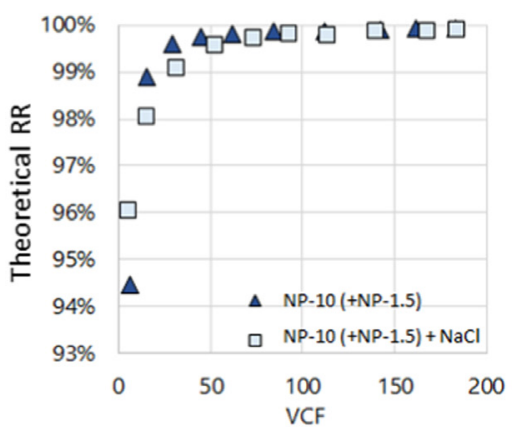

0.3 bar

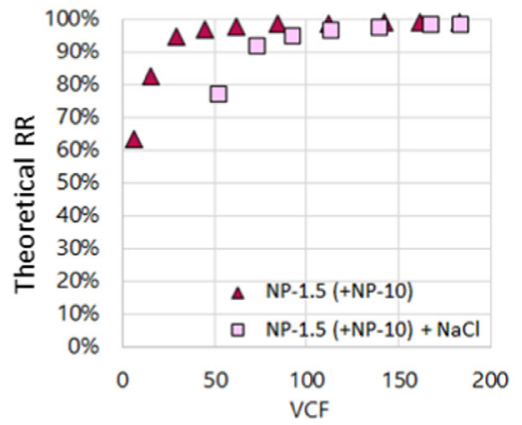

0.4 bar

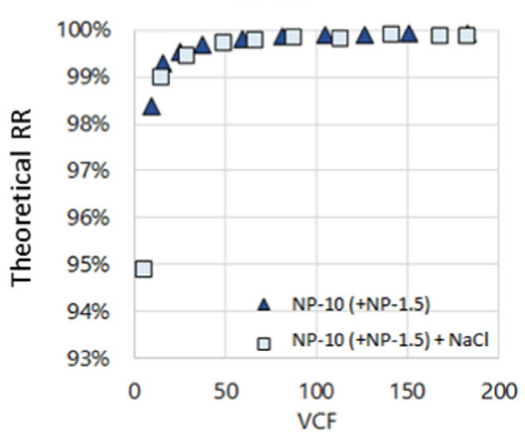

0.4 bar

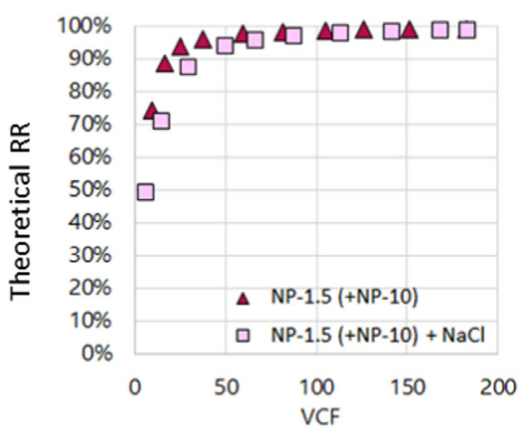

Fig. 11. Theoretical retention rate of a) NP-10 and b) NP-1.5 filtered in polydisperse suspension with or without NaCl as a function of VCF for different TMP (polydisperse suspension, VCF $=200$ ).

\subsection{Influence of polydispersity}

The retention of NP-10 (Fig. 7-a)) over time is influenced by the presence of NP-1.5 in the same way than by the addition of salt. A slight translation of the curves to the left reflects an improved retention rate. The retention of NP-1.5 during the filtration (Fig. 7-b)) is, however, decreased in the presence of NP-10. Indeed, at the beginning of filtration, the NP-1.5 are retained only about $60-80 \%$ against about $90 \%$ in the case of monodisperse suspension (in function of the TMP applied). As a result, the achievement of a theoretical RR of $99 \%$ for NP-1.5 in polydisperse suspension is obtained later in the filtration, for a VCF of about 150 achieved. The slight variation of NP-10 theoretical RR shows no modification of NP-10 experimental RR, which stays superior to $99 \%$. The number of NP-10 recovered in the permeate stays almost the same in monodisperse and in polydisperse suspensions (Fig. 8-a)). However, as in the case of $\mathrm{NaCl}$ adding, presence of NP-1.5 leads to a considerable increasing of the number of NP-10 remaining blocked at the membrane (Fig. 8-a)). Concerning NP-1.5, the presence of NP-10 has an important role in their retention. In fact, adding of NP-10 decrease the experimental RR from $87.1 \%$ to $74.0 \%$, from $84.27 \%$ to $62.7 \%$ and from $77.7 \%$ to $61.7 \%$ of NP-1.5 during their filtration under $0.2,0.3$ and 0.4 bar respectively. Presence of NP-10 leads to the increase of NP-1.5 passage through the membrane and thus, an increase of the NP-1.5 no. recovered in the permeate (Fig. 8-b)). Two assumptions may be put forward: a decrease of repulsive forces due to the mixture should (i) result in a greater penetration of NP-10 into membrane, or (ii) be the cause of the cake formation on the membrane surface composed of both NP-10 and NP-1.5 during the filtration of polydisperse suspensions. Thus, the cake reaches an improved stability, due to the structure achieved with both NPs size and a higher quantity of NP-10 blocked on membrane material. This modification of NP-10 retention may impact NP-1.5 passage. The most likely scenario is that solution passed through the cake of NPs is purer (retention increase with NPs deposit) and its passage through the membrane material flush it, sweeping NP-1.5 eventually deposited in membrane material (i.e. lower NP-1.5 are blocked into the membrane). The increase of the TMP of the filtration leads to a reduction of the NPs fraction blocked by the membrane. The autopsy of the membrane was performed by CLSM to locate the fouling of the membrane by the two NP sizes during the polydisperse suspension filtration. The identification and differentiation of each NP has been possible because their emission wavelengths are different (Table 2). Compared to the CLSM images obtained on membranes fouled by monodisperse suspensions, it appears that, in some areas, clusters of NP-1.5 are formed in the membrane material as it is shown in Fig. 9. Besides these clusters formed, a location of the fouling identical to the one observed after the filtration of monodisperse suspensions is observed. NP-10 are stopped in the skin of the membrane and on its surface whereas NP-1.5 penetrate in the entire membrane material. However, at higher TMP $($ TMP $=0.3$ and TMP $=$ 0.4 bar), penetration profiles show a normalized intensity reflecting the intensified presence of NP-1.5 on the membrane surface where the NP10 are also identified (Fig. 10). Thus, the participation of NP-1.5 to the membrane surface deposit is confirmed and amplified by the presence of NP-10. As it was showed, retention of NPs is affected by the polydispersity of the suspension. This retention modification affects the mass of NPs retained and thus, the permeability decline over the filtration run. The permeability is directly linked to the resistance generated by the fouling like it is shown by the Darcy law (Eq. (2)).

$J=\frac{T M P}{\mu \cdot\left(R_{m}+R_{f}\right)}$

where $\mathrm{J}$ is the permeate flux in $\mathrm{L} \cdot \mathrm{h}^{-1} \cdot \mathrm{m}^{-2}$, TMP is the transmembrane pressure in bar, $\mu$ is the permeate viscosity in Pa.s and $R_{m}$ and $R_{f}$ are respectively membrane material and the fouling resistance in $\mathrm{m}^{-1}$.

Thus, the resistances of fouling versus the mass of NPs retained during the filtration of monodisperse or polydisperse suspensions were evaluated. The slopes of this variation found are $1.51 \times 10^{14}$; $1.11 \times 10^{14}$ and $4.96 \times 10^{14}$ for fouling due to NP-1.5; NP-10 and NP$1.5+$ NP-10 respectively. Therefore, with equal mass retained by the membrane, $\mathrm{R}_{\mathrm{NP}-1.5+\mathrm{NP}-10}>\mathrm{R}_{\mathrm{NP}-1.5}>\mathrm{R}_{\mathrm{NP}-10}$. The retention of the NPs 
a)

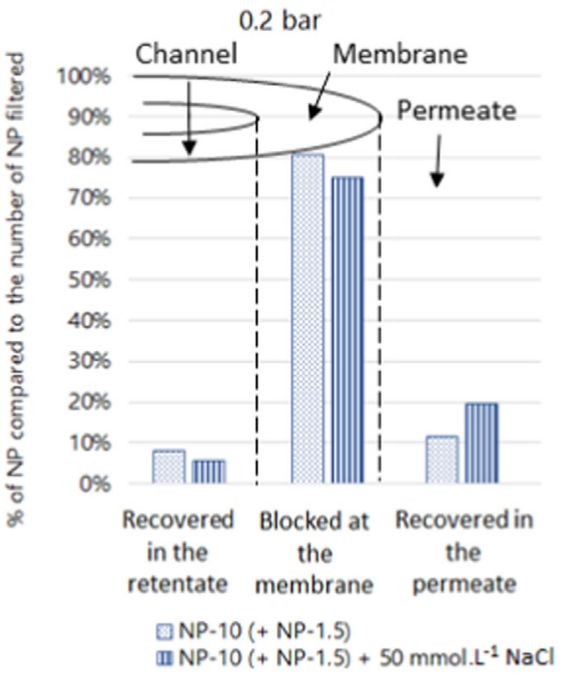

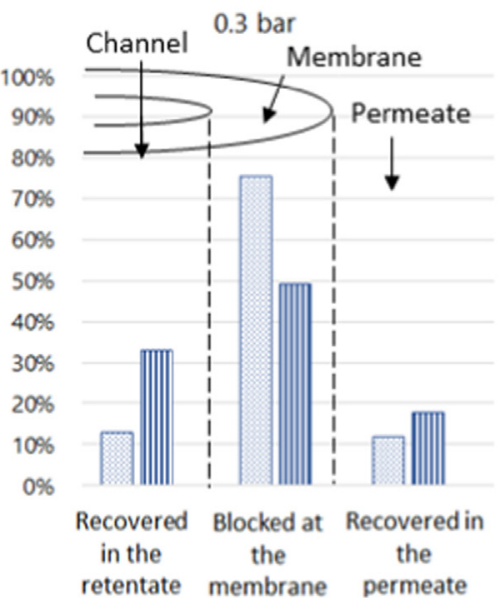

retentate membrane permeate

- $\mathrm{NP}-10(+\mathrm{NP}-1.5)$

II NP-10 $(+\mathrm{NP}-1.5)+50 \mathrm{mmol} \cdot \mathrm{L}^{-1} \mathrm{NaCl}$

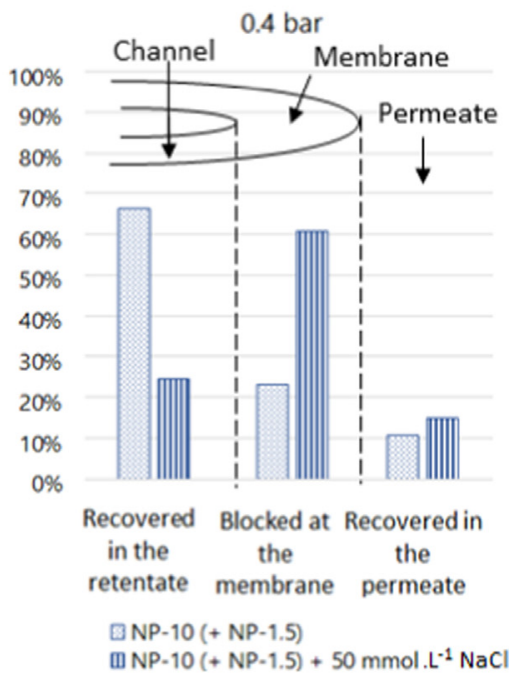

b)

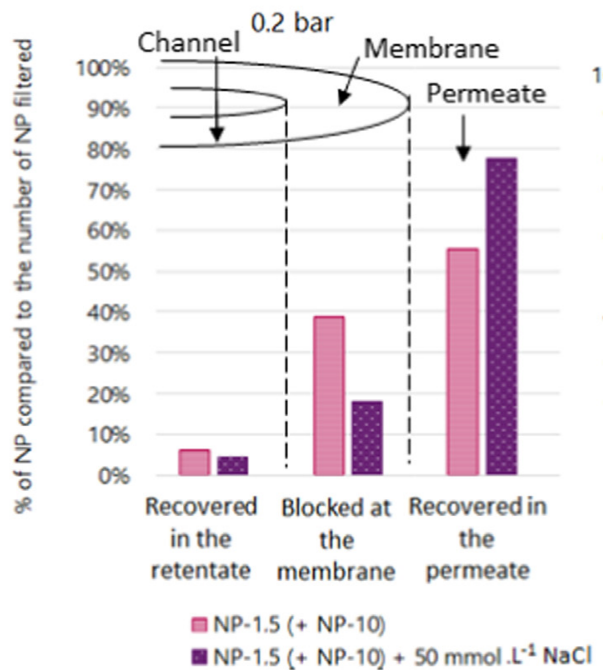

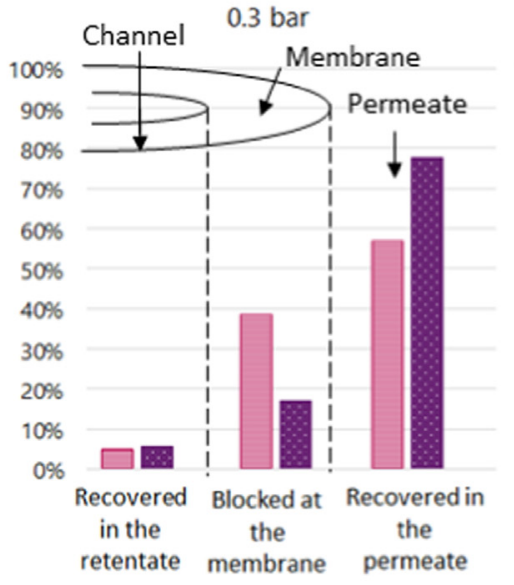

NP.1.5 (+ NP-10)

- $\mathrm{NP}-1.5(+\mathrm{NP}-10)+50 \mathrm{mmol} \cdot \mathrm{L}^{-1} \mathrm{NaCl}$

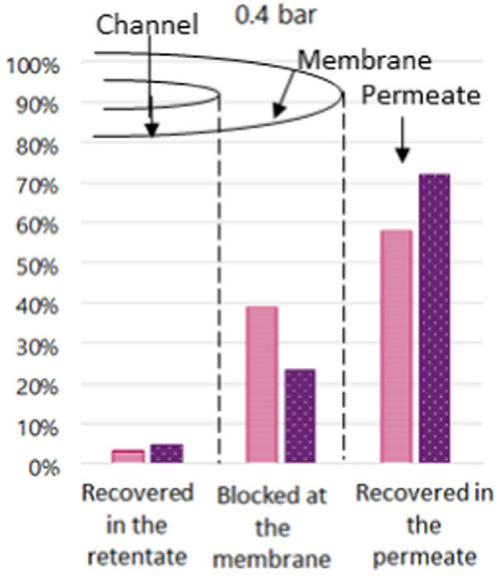

ENP.1.5 $(+N P-10)$

=NP-1.5 $(+N P-10)+50 \mathrm{mmol} \cdot \mathrm{L}^{-1} \mathrm{NaCl}$

Fig. 12. Recovery of a) NP-10 and b) NP-1.5 at the end of their filtration for different TMP as a function of the salinity (polydisperse suspension, VCF = 200).

in mixture causes a greater fouling. This result illustrates the great influence of the low NP-1.5 mass retained on the fouling resistance. In fact, the total mass of NPs engaged by the mixture is close to the NP-10 mass due to the important mass fraction of NP-10 compared to the one of NP-1.5 (NPs volume difference). Thanks to the profiles obtained on CLSM images, it has been demonstrated that the cake formed on the membrane surface is composed of NP-1.5 and NP-10. During the filtration of polydisperse suspensions, the increase of the NPs number in suspension as for an increase of salinity, may decrease the interactions between NP-NP and NP-membrane. As a result, the NP-1.5, smaller than the membrane pores pass more easily through the membrane and are found in the permeate generating a lower retention rate. The NP-10, with size close to the membrane pores, remain blocked on the membrane surface in larger amounts causing greater fouling and an almost constant retention rate due to the very small amount recovered in the permeate. The effect of NP-1.5 adding is the same as the adding of salt but to a lesser degree in terms of repulsion. Throughout the filtration, the transfer of NP-1.5 is limited and the retention rate increases. The NP-1.5 are retained by the layer of NP-10 deposited on the surface of the membrane and then participate in the cake formation. Hermia models were applied to the experimental flux data obtained during the filtration of polydisperse suspensions. Mechanisms found are unchanged compared to monodisperse filtrations of each NPs size. During the first step of the filtration, standard pore blocking is identified, followed by cake filtration. However, establishment of fouling mechanisms seems to follow behavior observed during monodisperse NP10 filtrations. Standard pore blocking lasts less than when NP-1.5 are filtered individually. To sum up, the effect of the presence of another NPs size is not the same depending on the NP size considered. For NP10 , the presence of NP-1,5 in the quantity studied shows a lower influence in their filtration with a quasi-total arrest of these NPs by the membrane (experimental RR $>99 \%$ ). The retention does not vary, but the presence of NP-1.5 seems to decrease the membrane-NP-10 repulsion and contributes to a greater accumulation on the membrane surface and therefore causes a greater blocking at the origin of a greater drop in permeability of the membrane. The modification of the NPs suspension by adding NP-10 present an influence much more important for NP-1.5. As it is showed in Table 2, the zeta potential of feed mixing NP-1.5 and NP-10 is lower than the zeta potential observed when NP1.5 are filtered individually. This observation may result in a decrease of NP-1.5-membrane repulsions and their greater preferential passage, a drop in the retention rate and an increase of their recovery in permeate. Fouling models found with Hermia models show a standard pore blocking occurring much faster with presence of both NPs sizes. As the experiment is conducted, the NP-1.5 participates to the NP-10 cake formed on membrane surface, which contributes to the increase of fouling resistance and a more important flux loss. Cake filtration is predominant over most of the experiment. These results are confirmed 

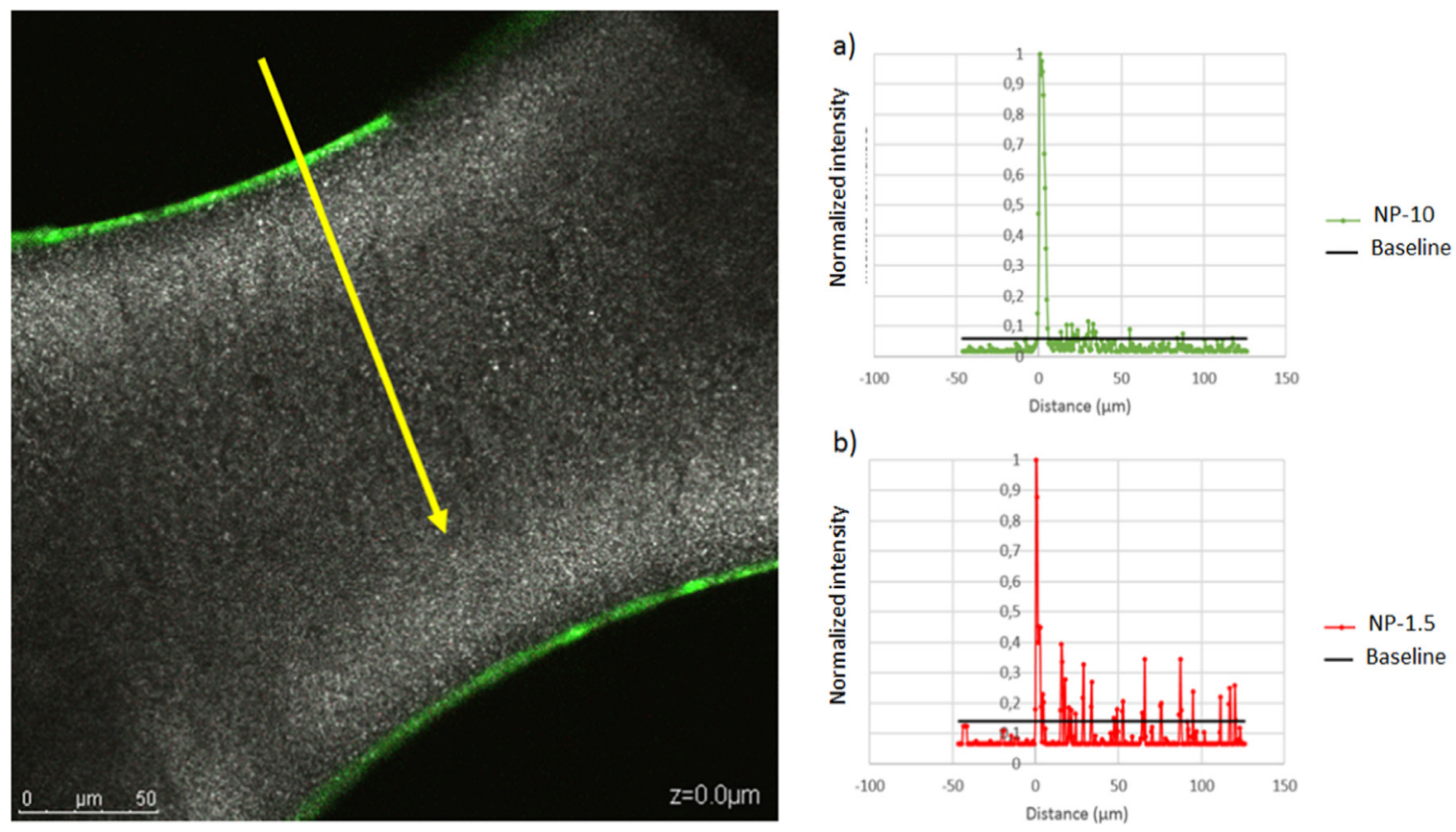

Fig. 13. CSLM image (where the gray, green and red scales correspond respectively to membrane, NP-10 and NP-1.5) and penetration profiles of a) NP-10 and b) NP1.5 in membrane after their filtration in polydisperse suspension with $50 \mathrm{mmol} \mathrm{L}^{-1}$ of $\mathrm{NaCl}$ (polydisperse suspension, $\mathrm{TMP}=0.2 \mathrm{bar}$, VCF $=200$ ).

by the observations by CLSM where one clearly distinguishes the presence of a cake and the presence of the NP-1,5 inside this one. It must also be remembered that the initial quantity of injected NPs is greater, leading to an accentuation of the phenomenon.

\subsection{Filtration of polydisperse suspension with salinity}

Salinity $\left(50 \mathrm{mmol} \mathrm{L}^{-1}\right.$ of $\mathrm{NaCl}$ ) have been added to polydisperse feed suspension. Once again, theoretical RR of NP-10 is not greatly affected by the adding of salt: a slight reduction in the presence of $\mathrm{NaCl}$ is observed (Fig. 11-a). However, this theoretical RR is not inferior to $90 \%$ even at the beginning of the filtration and it reaches quickly more than $99 \%$ after a VCF of about 25 achieved whatever the TMP applied. The theoretical retention rate of NP-1.5 in polydisperse suspension is greatly modified by the presence of $\mathrm{NaCl}$ (Fig. 11-b). At the beginning of the filtration run, in the presence of salt, a theoretical RR of only $20 \%$ is observed under 0.2 bar. The decrease of retention with adding of salt is a phenomenon largely observed in membrane filtration [30,31]. For example, Labbez et al. [32] explained that it is possible that this RR decrease is due to a stronger screening effect of the ions on the membrane charged sites, leading to a decrease of the membrane repulsive forces on the ions. This theoretical RR increases with the progress of the filtration and reaches a value of approximately $99 \%$ after a VCF of about 160 . The number of NPs blocked at the membrane is modified by the presence of $\mathrm{NaCl}$ in the polydisperse suspension (Fig. 12). The increase in the recovery of NP-1.5 is due to the increase in the passage of $\mathrm{NP}$ in the permeate reflecting a strong decrease of the repulsion effects between the NP-1.5 and the membrane. In fact, the number of NP-1.5 recovered in the retentate at the end of the filtration does not vary significantly. With salt, the effects of charges remain pronounced inside the membrane and a large quantity of NP-1.5 passed through the membrane while it stayed blocked in the membrane without salt. The same comportment is observed for the NP-10 but at a lesser degree. The presence of NP-1.5 and/or salt in feed suspension leads to an important increase of NP-10 quantity bounded to the membrane. This variation could be explained by a decrease of repulsive forces between NPs and between NPs and membrane. The combined addition of NP-1.5 and $\mathrm{NaCl}$ reinforces this effect and thus the low recovery in the permeate and the retentate compared to the number of NP-10 blocked at the membrane.

Once again, fouled membrane autopsy was realized by CLSM. The imaging of the membranes shows the fluorescent signal reflecting the presence of NP-1.5 on the entire membrane after the filtrations in the presence of NP-10 and NaCl (Fig. 13). The presence of NP-1.5 is identified in the final cake on membrane surface constituting a small thickness. Few clusters are detected in membrane material but much less than when polydisperse suspensions do not contain salt (Figs. 10 and 14) reflecting a blocking in the membrane decreased and a passage of NP-1.5 in the permeate greatly increased. During filtrations realized without $\mathrm{NaCl}$, membrane-NP-1.5 repulsions are weaker at the surface due to the presence of NP-10 but stronger in the membrane structure where no NP-10 are present. With salt, clusters of NP-1.5 in membrane materiel are less detected. It can be explained by the fact that the presence of $\mathrm{NaCl}$ leads to a decrease of repulsion between membrane and NP-1.5. Adding of salt at significant concentration leads to mask the membrane charges [32] and so, decrease the membrane-NP attraction. The study of fouling with Hermia models becomes more difficult with the complexification of the feed suspension. In fact, the segmentation of the portions to identify different models becomes difficult and the correlation coefficients obtained are rarely greater than 0.7. After a VCF of 170 achieved, a cake filtration is identified whatever the TMP applied. However, before this VCF, it is difficult to advance a fouling mechanism operating with certitude. Both standard blocking model and complete model present correlation coefficient superior or equal to 0.7 but only on certain portions of data. Complete pore blocking has been found for the first section of the filtration for filtration of NP-10 with $\mathrm{NaCl}$ and the increase of NP-10 size due to an agglomeration. The same scenario of aggregation can occur with presence of $\mathrm{NaCl}$ and NP-1.5. In fact, size distribution of the polydisperse suspensions remains difficult to obtain with Zetasizer because NPs used are not composed of the same material so refractive indexes are not the same making that sizes announced are not reliable. NP-1.5 are found on the entire depth of the membrane and NP-10 in the membrane skin so a standard pore blocking can effectively operate during the first step of the filtration. Finally, the presence of salinity in a polydisperse suspension of NPs does not engender the same effects on the two sizes of 

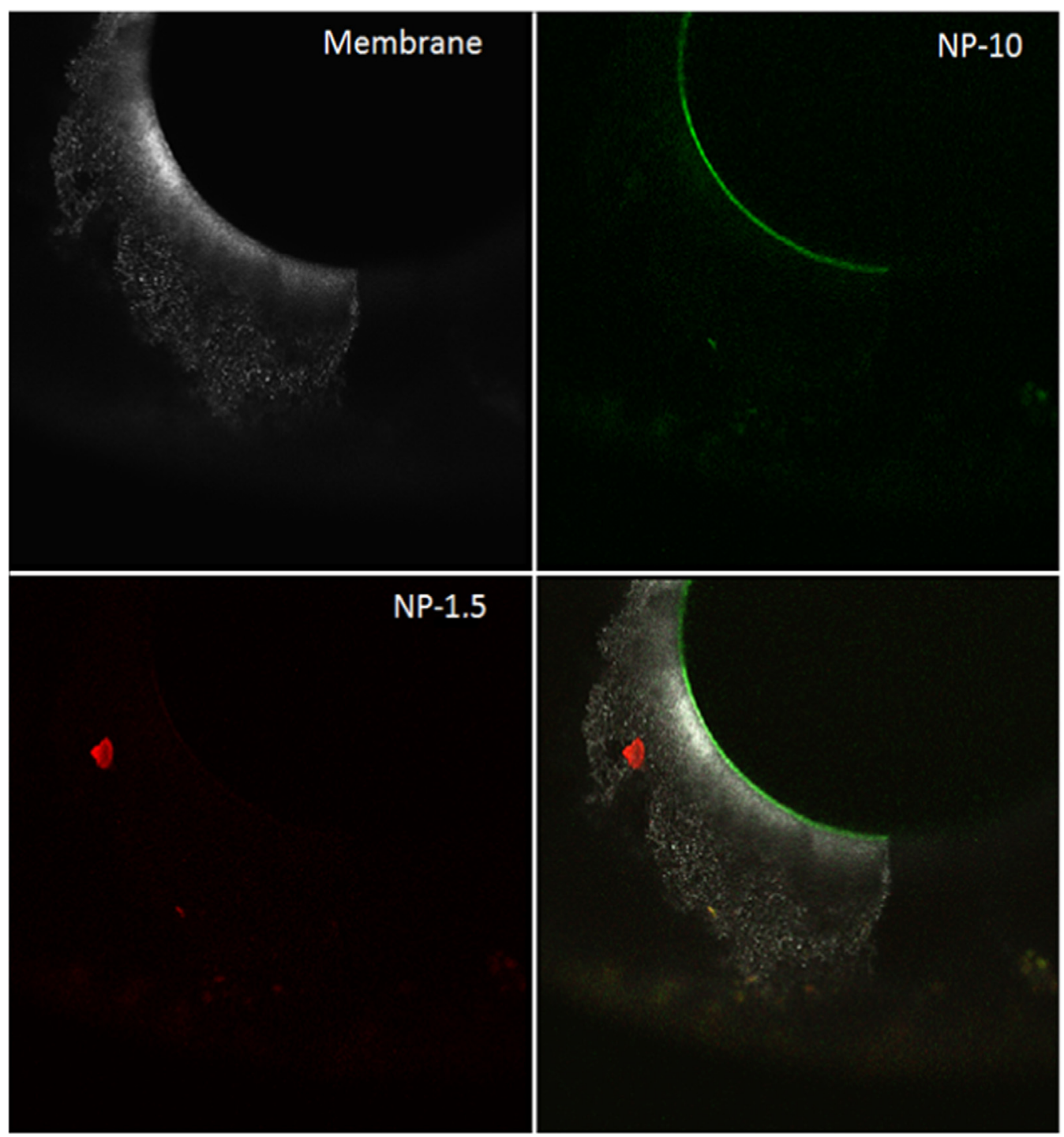

Fig. 14. Scans obtained by CLSM with the visualization of membrane microstructure, NP-10 and NP-1.5 and superimposition of these 3 scans (bottom right) for fouled by polydisperse suspension with $50 \mathrm{mmol} \mathrm{L}^{-1}$ of $\mathrm{NaCl}$ (TMP $=0.2 \mathrm{bar}$, VCF $=200$ ).

NPs. While the retention of NP-10 did not change much with the addition of $\mathrm{NaCl}$, the NP-1.5 more pass through the membrane, greatly reducing their retention, especially at the beginning of filtration. However, retention increased during filtration with the establishment of fouling - by standard and complete pore blockage followed by cake filtration - to achieve theoretical retentions greater than $99 \%$ for both NP sizes at the end of the filtration $(\mathrm{VCF}=200)$. The fouling characterization by CLSM showed a presence of NP-10 in the membrane skin and a deposition on the surface, thus, no effect of the presence of NP-1.5 combined with $\mathrm{NaCl}$ on NP-10 location have been highlighted. The visualization of the NP-1.5 by CLSM revealed the participation of these NPs to the cake formed on the membrane surface. The presence of $\mathrm{NP}-10$ and $\mathrm{NaCl}$ thus reduce the repulsion effects between the NP-1.5 and the membrane, promoting their passage through the membrane and their recovery in the permeate.

\section{Conclusion}

NPs retention and location of NPs retained by the membrane have been studied in monodisperse or polydisperse suspension with or without $\mathrm{NaCl}$ during their filtration. To do this, characterization techniques and complementary and multi-scale analysis methods were used. The results have been linked to reveal precise and reliable evolutions.
Whatever the feed suspension filtered or the TMP applied, an experimental RR of $99 \%$ has been obtained for NP-10. Location of NP-10 after filtration realized by CLSM showed a retention in membrane skin and on membrane surface. For NP-10, the addition of salinity and/or NP-1.5 decreases the NP-NP and NP-membrane repulsions as it is justified by zeta potential values presented in Table 2. Thus, the amount of NP-10 blocked at the membrane is increased and consist in agglomerates preferentially blocked on the membrane surface. However, the adding of NP-10 and NaCl in NP-1.5 suspension leads to a decrease of NP-1.5membrane repulsion leading to an important decrease of the retention rate. This RR is also dependent on TMP applied and decreases when TMP is increased. Location of NP-1.5 blocked at the membrane by CLSM show a retention in the entire membrane thickness. Simultaneous filtration of NP-1.5 with NP-10 leads to their participation to the cake formed at the membrane surface. The application of a greater TMP presents no effect on NP-10 retention and location in the membrane at the end of the filtration whatever the suspension filtered (monodisperse or polydisperse suspensions, with or without $\mathrm{NaCl}$ ). However, increase of TMP leads to an increase of NP-1.5 passage through the membrane. This phenomenon engenders a modification of retention in the membrane material and an increase of NP-1.5 recovery in the permeate. Several remarks can be made regarding the fouling models identified during the filtration. The addition of $\mathrm{NaCl}$ leads to an increase of the 
average size of NP-10 in monodisperse suspension and causes the setting up a complete pore blocking mechanism. The addition of $\mathrm{NaCl}$ in the polydisperse suspensions leads to the same phenomenon of NPs aggregation and to a faster blocking of the pores on the membrane surface. For each experiment conducted, cake filtration was observed on a second step of filtration. The establishment of the cake filtration is done later than when the suspension does not contain salt. This result justifies the greater passage of NP-1.5 through the membrane and the decrease in the theoretical RR observed in the presence of salt. These results are finally in agreement with the identified CLSM profiles for each of the two NP sizes.

\section{Acknowledgement}

"The project leading to this publication has received funding from Excellence Initiative of Aix-Marseille University - A*MIDEX, a French "Investissements d'Avenir" programme. It has been carried out in the framework of the Labex MEC." The authors are grateful to Aquasource for providing the new generation membranes used during this work.

\section{References}

[1] R. Hischier, T. Walser, Life cycle assessment of engineered nanomaterials: state of the art and strategies to overcome existing gaps, Sci. Total Environ. 425 (2012) 271-282, http://dx.doi.org/10.1016/j.scitotenv.2012.03.001.

[2] F. Gottschalk, B. Nowack, The release of engineered nanomaterials to the environment, J. Environ. Monit. 13 (2011) 1145, http://dx.doi.org/10.1039/ c0em00547a.

[3] F. Gottschalk, C. Lassen, J. Kjoelholt, F. Christensen, B. Nowack, Modeling Flows and Concentrations of Nine Engineered Nanomaterials in the Danish Environment, Int. J. Environ. Res. Public. Health 12 (2015) 5581-5602, http://dx.doi.org/10. 3390/ijerph120505581.

[4] T.Y. Sun, F. Gottschalk, K. Hungerbühler, B. Nowack, Comprehensive probabilistic modelling of environmental emissions of engineered nanomaterials, Environ. Pollut. 185 (2014) 69-76, http://dx.doi.org/10.1016/j.envpol.2013.10.004.

[5] F. Gottschalk, T. Sonderer, R.W. Scholz, B. Nowack, Modeled environmental concentrations of engineered nanomaterials ( $\mathrm{TiO} 2, \mathrm{ZnO}, \mathrm{Ag}$, CNT, fullerenes) for different regions, Environ. Sci. Technol. 43 (2009) 9216-9222.

[6] A.B.A. Boxall, Q. Chaudhry, A. Ardern-Jones, B. Jefferson, C.D. Watts, A.B.A. Boxall, C. Sinclair, A.D. Baxter-Jones, R. Aitken, C. Watts, Q. Chaudrhry, Current and Future Predicted Environmental Exposure to Engineered Nanoparticles. 〈https://www.scienceopen.com/document?Vid = 7a5a2f43-9b0e-449d-b0702c500ff54bd7> (Accessed 6 February 2018), 2008.

[7] R.J.B. Peters, G. van Bemmel, N.B.L. Milani, G.C.T. den Hertog, A.K. Undas, M. van der Lee, H. Bouwmeester, Detection of nanoparticles in Dutch surface waters, Sci. Total Environ. 621 (2018) 210-218, http://dx.doi.org/10.1016/j.scitotenv.2017. 11.238 .

[8] R.J.B. Peters, Z.H. Rivera, G. van Bemmel, H.J.P. Marvin, S. Weigel, H. Bouwmeester, Development and validation of single particle ICP-MS for sizing and quantitative determination of nano-silver in chicken meat, Anal. Bioanal. Chem. 406 (2014) 3875-3885, http://dx.doi.org/10.1007/s00216-013-7571-0.

[9] R. Peters, Z. Herrera-Rivera, A. Undas, M. van der Lee, H. Marvin, H. Bouwmeester, S. Weigel, Single particle ICP-MS combined with a data evaluation tool as a routine technique for the analysis of nanoparticles in complex matrices, J. Anal. At. Spectrom. 30 (2015) 1274-1285, http://dx.doi.org/10.1039/C4JA00357H.

[10] N. Wu, Y. Wyart, J. Rose, B. Angeletti, P. Moulin, Application of membrane processes in fractionation of elements in river water, Water Sci. Technol. (2015) (wst2015444).

[11] X. Zhao, R. Liu, Recent progress and perspectives on the toxicity of carbon nanotubes at organism, organ, cell, and biomacromolecule levels, Environ. Int. 40 (2012) 244-255, http://dx.doi.org/10.1016/j.envint.2011.12.003.

[12] A. Nel, T. Xia, L. Mädler, N. Li, Toxic potential of materials at the nanolevel, Science
311 (2006) 622-627, http://dx.doi.org/10.1126/science.1114397.

[13] A. Shiohara, A. Hoshino, K. Hanaki, K. Suzuki, K. Yamamoto, On the Cyto-Toxicity Caused by Quantum Dots, Microbiol. Immunol. 48 (2004) 669-675, http://dx.doi. org/10.1111/j.1348-0421.2004.tb03478.x.

[14] P.J. Borm, D. Robbins, S. Haubold, T. Kuhlbusch, H. Fissan, K. Donaldson, R. Schins, V. Stone, W. Kreyling, J. Lademann, J. Krutmann, D. Warheit, E. Oberdorster, The potential risks of nanomaterials: a review carried out for ECETOC, Part. Fibre Toxicol. 3 (2006) 11, http://dx.doi.org/10.1186/1743-8977-3-11.

[15] H. Guo, Y. Wyart, J. Perot, F. Nauleau, P. Moulin, Application of magnetic nanoparticles for UF membrane integrity monitoring at low-pressure operation, J. Membr. Sci. 350 (2010) 172-179, http://dx.doi.org/10.1016/j.memsci.2009.12. 025 .

[16] N. Wu, Y. Wyart, L. Siozade, G. Georges, P. Moulin, Characterization of ultrafiltration membranes fouled by quantum dots by confocal laser scanning microscopy, J. Membr. Sci. 470 (2014) 40-51, http://dx.doi.org/10.1016/j.memsci. 2014.07.001.

[17] S.-C. Chen, D. Segets, T.-Y. Ling, W. Peukert, D.Y.H. Pui, An experimental study of ultrafiltration for sub-10nm quantum dots and sub-150 nm nanoparticles through PTFE membrane and Nuclepore filters, J. Membr. Sci. 497 (2016) 153-161, http:// dx.doi.org/10.1016/j.memsci.2015.09.022.

[18] M. Le Hir, Y. Wyart, G. Georges, L. Siozade, P. Moulin, Nanoparticles retention potential of multichannel hollow fiber drinking water production membrane, J. Membr. Sci. Res. (2017), http://dx.doi.org/10.22079/jmsr.2017.69079.1150.

[19] M.Le Hir, Y.Wyart, G.Georges, L.Siozade, P.Moulin, Fouling of drinking water production membrane by nanoparticles, 2016.

[20] M. Le Hir, Y. Wyart, G. Georges, L. Siozade, P. Moulin, Nanoparticles retention potential of drinking water production membranes, 2016.

[21] H. Lee, D. Segets, S. Süß, W. Peukert, S.-C. Chen, D.Y.H. Pui, Liquid filtration of nanoparticles through track-etched membrane filters under unfavorable and different ionic strength conditions: experiments and modeling, J. Membr. Sci. 524 (2017) 682-690, http://dx.doi.org/10.1016/j.memsci.2016.11.023.

[22] D. Jassby, S.-R. Chae, Z. Hendren, M. Wiesner, Membrane filtration of fullerene nanoparticle suspensions: effects of derivatization, pressure, electrolyte species and concentration, J. Colloid Interface Sci. 346 (2010) 296-302, http://dx.doi.org/10. 1016/j.jcis.2010.03.029.

[23] S.-R. Chae, T. Noeiaghaei, H.-C. Jang, S. Sahebi, D. Jassby, H.-K. Shon, P.-K. Park, J.-O. Kim, J.-S. Park, Effects of natural organic matter on separation of the hydroxylated fullerene nanoparticles by cross-flow ultrafiltration membranes from water, Sep. Purif. Technol. 140 (2015) 61-68, http://dx.doi.org/10.1016/j.seppur. 2014.11.011.

[24] J. Olabarrieta, O. Monzón, Y. Belaustegui, J.-I. Alvarez, S. Zorita, Removal of TiO2 nanoparticles from water by low pressure pilot plant filtration, Sci. Total Environ. 618 (2018) 551-560, http://dx.doi.org/10.1016/j.scitotenv.2017.11.003.

[25] D.A. Ladner, M. Steele, A. Weir, K. Hristovski, P. Westerhoff, Functionalized nanoparticle interactions with polymeric membranes, J. Hazard. Mater. 211-212 (2012) 288-295, http://dx.doi.org/10.1016/j.jhazmat.2011.11.051.

[26] S. Kim, M. Marion, B.-H. Jeong, E.M.V. Hoek, Crossflow membrane filtration of interacting nanoparticle suspensions, J. Membr. Sci. 284 (2006) 361-372, http:// dx.doi.org/10.1016/j.memsci.2006.08.008.

[27] J. Hermia, Constant pressure blocking filtration laws - application to power-law non-newtonian fluids, Trans. IChemE 60 (1982) 111-120.

[28] M.-J. Corbatón-Báguena, S. Álvarez-Blanco, M.-C. Vincent-Vela, Fouling mechanisms of ultrafiltration membranes fouled with whey model solutions, Desalination 360 (2015) 87-96, http://dx.doi.org/10.1016/j.desal.2015.01.019.

[29] V.V. Tarabara, I. Koyuncu, M.R. Wiesner, Effect of hydrodynamics and solution ionic strength on permeate flux in cross-flow filtration: direct experimental observation of filter cake cross-sections, J. Membr. Sci. 241 (2004) 65-78, http://dx. doi.org/10.1016/j.memsci.2004.04.030.

[30] J. Luo, Y. Wan, Effect of highly concentrated salt on retention of organic solutes by nanofiltration polymeric membranes, J. Membr. Sci. 372 (2011) 145-153, http:// dx.doi.org/10.1016/j.memsci.2011.01.066.

[31] E. Alventosa-deLara, S. Barredo-Damas, E. Zuriaga-Agusti, M.I. Alcaina-Miranda, M.I. Iborra-Clar, Ultrafiltration ceramic membrane performance during the treatment of model solutions containing dye and salt, Sep. Purif. Technol. 129 (2014) 96-105, http://dx.doi.org/10.1016/j.seppur.2014.04.001.

[32] C. Labbez, P. Fievet, A. Szymczyk, A. Vidonne, A. Foissy, J. Pagetti, Analysis of the salt retention of a titania membrane using the "DSPM" model: effect of $\mathrm{pH}$, salt concentration and nature, J. Membr. Sci. 208 (2002) 315-329. 